\title{
Trivalent Subunit Vaccine Candidates for COVID-19 and Their Delivery Devices
}

\author{
Oscar A. Ortega-Rivera, Matthew D. Shin, Angela Chen, Veronique Beiss, Miguel A. Moreno-Gonzalez, \\ Miguel A. Lopez-Ramirez, Maria Reynoso, Hong Wang, Brett L. Hurst, Joseph Wang, \\ Jonathan K. Pokorski,* and Nicole F. Steinmetz*
}

Cite This: J. Am. Chem. Soc. 2021, 143, 14748-14765

Read Online

ABSTRACT: The COVID-19 pandemic highlights the need for platform technologies enabling rapid development of vaccines for emerging viral diseases. The current vaccines target the SARS-CoV-2 spike (S) protein and thus far have shown tremendous efficacy. However, the need for cold-chain distribution, a prime-boost administration schedule, and the emergence of variants of concern (VOCs) call for diligence in novel SARS-CoV-2 vaccine approaches. We studied 13 peptide epitopes from SARS-CoV-2 and identified three neutralizing epitopes that are highly conserved among the VOCs. Monovalent and trivalent COVID-19 vaccine candidates were formulated by chemical conjugation of the peptide epitopes to cowpea mosaic virus (CPMV) nanoparticles and virus-like particles

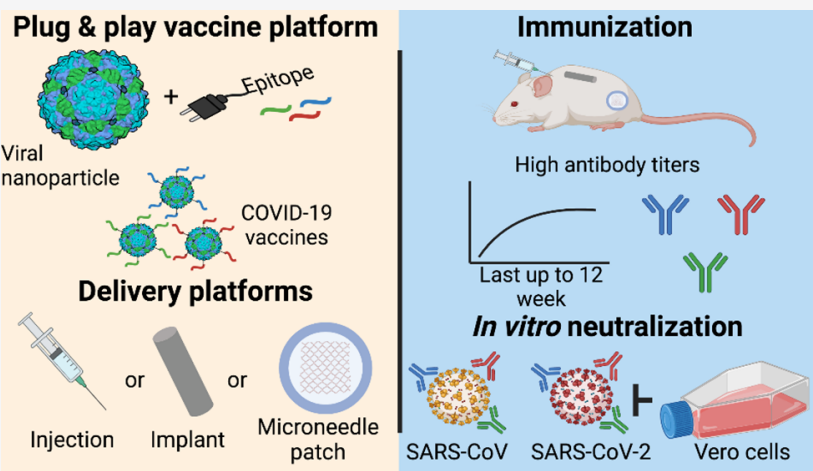
(VLPs) derived from bacteriophage $\mathrm{Q} \beta$. Efficacy of this approach was validated first using soluble vaccine candidates as solo or trivalent mixtures and subcutaneous prime-boost injection. The high thermal stability of our vaccine candidates allowed for formulation into single-dose injectable slow-release polymer implants, manufactured by melt extrusion, as well as microneedle ( $\mathrm{MN}$ ) patches, obtained through casting into micromolds, for prime-boost self-administration. Immunization of mice yielded high titers of antibodies against the target epitope and $S$ protein, and data confirms that antibodies block receptor binding and neutralize SARS-CoV and SARS-CoV-2 against infection of human cells. We present a nanotechnology vaccine platform that is stable outside the cold-chain and can be formulated into delivery devices enabling single administration or self-administration. CPMV or Q $\beta$ VLPs could be stockpiled, and epitopes exchanged to target new mutants or emergent diseases as the need arises.

\section{INTRODUCTION}

The rise of severe acute respiratory syndrome coronavirus 2 (SARS-CoV-2) leading to the coronavirus disease (COVID-19) pandemic highlights the need for platform technologies enabling rapid development of vaccines for emerging viral diseases. ${ }^{1}$ An unprecedented collaboration between key players in the vaccine R\&D industry and academic laboratories around the world led to the development, emergency authorization, and administration of millions of doses of nanotechnology-based vaccines around the globe within record time. ${ }^{2,3}$ However, successful vaccination programs are still mostly limited to developed countries, ${ }^{3}$ and the roll-out of mass vaccinations was burdened by undesirable attributes, such as the requirement of storage at ultralow temperatures, delivery via injection thus requiring medical staff, the requirement of a prime-boost vaccination schedule, and methods to scale up the current COVID-19 vaccines.

The difficulties faced during the COVID-19 pandemic offer learning opportunities to improve upon for future vaccine efforts against any emerging pathogen. Therefore, it is critical to develop novel platform technologies and delivery devices to produce vaccines that are highly stable, do not require coldchain distribution, are effective after a single dose, are massively scalable with ease of fabrication, and can be self-administered.

Toward these goals, we developed plant virus- and bacteriophage-based COVID-19 vaccine candidates displaying peptide epitopes from the SARS-CoV-2 S protein. The virus nanoparticle, here cowpea mosaic virus (CPMV) or a virus-like particle derived from bacteriophage $\mathrm{Q} \beta$, serves as an adjuvant and delivery technology enabling efficient uptake by draining lymph nodes and processing by professional antigen-presenting cells. $^{4-6}$

Received: June 25, 2021

Published: September 7, 2021 
Table 1. B Cell Epitopes from SARS-CoV-2 S Protein

\begin{tabular}{|c|c|c|c|c|c|c|c|}
\hline$S$ domain & location $\left(\underline{\text { name }}^{a}\right)$ & sequence & original paper peptide ID & length (aa) & $\mathrm{pI}$ & water solubility & ref \\
\hline S1 & $369-\underline{386}$ & YNSASFSTFKCYGVSPTK & $\mathrm{n} / \mathrm{a}$ & 18 & 9.35 & poor & 24 \\
\hline S2 & $806-\underline{820}$ & LPDPSKPSKRSFIED & $\mathrm{n} / \mathrm{a}$ & 15 & 6.95 & good & 25 \\
\hline S1 & $456-\underline{460}$ & FRKSN & $\mathrm{n} / \mathrm{a}$ & 5 & 11.39 & good & \\
\hline S2 & $809-\underline{826}$ & PSKPSKRSFIEDLLFNKV ${ }^{b, c}$ & $\mathrm{~S} 21 \mathrm{P} 2$ & 18 & 10.61 & good & 26 \\
\hline S1 & $553-\underline{570}$ & TESNKKFLPFQQFGRDIA & S14P5 & 18 & 9.64 & good & \\
\hline S1 & $553-\underline{564}$ & TESNKKFLPFQQ & S1-93 & 12 & 9.64 & good & 27 \\
\hline S1 & $625-\underline{636}$ & HADQLTPTWRVY & S1-105 & 12 & 7.54 & poor & \\
\hline S2 & $1148-\underline{1159}$ & FKEELDKYFKNH & $S 2-78$ & 12 & 7.53 & good & \\
\hline S1 & $92-\underline{106}$ & FASTEKSNIIRGWIF $^{b}$ & S92-106 & 15 & 9.87 & poor & 28 \\
\hline S1 & $139-\underline{153}$ & PFLGVYYHKNNKSWM $^{b}$ & S139-153 & 15 & 10.21 & poor & \\
\hline S1 & $406-\underline{420}$ & EVRQIAPGQTGKIAD & S406-420 & 15 & 6.92 & good & \\
\hline $\mathrm{S} 1$ & $439-\underline{454}$ & NNLDSKVGGNYNYLYR ${ }^{b}$ & S439-454 & 16 & 9.10 & good & \\
\hline S1 & $455-\underline{469}$ & LFRKSNLKPFERDIS & $S 455-469$ & 15 & 10.67 & good & \\
\hline
\end{tabular}

${ }^{a}$ Nomenclature: in the following the peptides are referred to the 3-4 number code; underlined in bold. ${ }^{b}$ Required F127 for stable conjugation to CPMV. ${ }^{c}$ Required F127 for stable conjugation to $\mathrm{Q} \beta$.

CPMV is a plant virus that self-assembles into 30 -nm-sized icosahedral capsids that consist of 60 copies each of a small and large coat protein unit; ${ }^{7}$ the particles have pseudo-T3 symmetry. CPMV can be produced through molecular farming in plants and has been validated as a vaccine platform in preclinical models, ${ }^{8}$ and more recently its application as cancer immunotherapy has been reported. ${ }^{9,10} \mathrm{Q} \beta$ is expressed as a virus-like particle (VLP) that consists of 180 identical copies of a coat protein, and the 30 -nm-sized particles have T3 symmetry. The $\mathrm{Q} \beta$-based nanoparticles can be mass-produced through bacterial fermentation with several $\mathrm{Q} \beta$-based vaccine candidates undergoing clinical testing. ${ }^{5,6,11} \mathrm{CPMV}$ and $\mathrm{Q} \beta$ have high thermal stability and therefore can undergo hot-melt extrusion to formulate slow-release polymer blends as well as fast-soluble microneedle delivery devices. ${ }^{12-14}$ We adapted these methods to produce COVID-19 vaccine candidates and their delivery devices. Molecular farming of CPMV, fermentation of $\mathrm{Q} \beta$, hot melt extrusion of polymer blends, and microneedle (MN) polymer micromolding are scalable techniques and therefore suitable approaches for the development of novel vaccine platform technologies.

Any vaccine requires an antigen, adjuvant, and delivery technology; for the target antigen, we focused on B cell epitopes from the SARS-CoV-2 S protein. Current COVID-19 vaccines and most candidates undergoing development target full-length spike (S) glycoprotein or the receptor binding domain (RBD), ${ }^{15,16}$ which play a key role in viral entry. ${ }^{17}$ While vaccines based on full-length $S$ protein have shown tremendous efficacy, concerns have been raised because of reduced efficacy against emerging variants of SARS-CoV-2 variants of concern (VOCs). ${ }^{18}$ We report on our efforts using B cell epitopes that are highly conserved among SARS-CoV-2 variants. Another rationale to target $\mathrm{B}$ cell epitopes is that antibody responses are more targeted as compared to the broad spectrum of antibody and cellular responses when immunization is carried out with fulllength protein. Earlier studies on SARS and MERS vaccine candidates have pointed to risks of antibody-dependent enhancement $(\mathrm{ADE})$ of infection as well as cellular response mediated Th2 immunopathology. ${ }^{19-21}$ While this phenomenon has not been reported from recovered patients or from the multiple COVID-19 vaccines already administrated to millions of people, ${ }^{20,21}$ developing peptide epitope-based SARS-CoV-2 vaccine strategies may yield a vaccine focused on conserved domains with antibody responses consistently targeting and neutralizing across VOCs or other coronaviruses.

In this work, we report the development of trivalent CPMVand $\mathrm{Q} \beta$-based COVID-19 vaccine candidates. Here, vaccine valency is defined as the number of $S$ protein epitopes combined into a single formulation; ${ }^{22}$ for example, a trivalent COVID-19 vaccine candidate contains three unique SARS-CoV-2 peptide epitopes. Each unique peptide epitope was chemically-displayed on its own respective nanocarrier - either CPMV or $\mathrm{Qb}-$ and trivalent formulations were realized by mixing $(1: 1: 1)$ three different monovalent CPMV-peptide conjugates or three different monovalent $\mathrm{Qb}$-peptide conjugates together. We demonstrated the efficacy of the vaccine candidates when administered using a prime-boost schedule and injection or microneedle patches, the latter offering opportunity for selfadministration. We also demonstrate the efficacy of a slowrelease injectable implant after a single administration. Antibody titers and immune responses were studied, and neutralization potency was assayed using a surrogate receptor binding assay as well as a SARS-CoV-2 neutralization assay using human cells.

\section{METHODS}

CPMV Propagation. CPMV viral nanoparticles were propagated and purified as established elsewhere. ${ }^{23}$ Purified CPMV was stored in potassium phosphate (KP) buffer $(0.1 \mathrm{M}, \mathrm{pH} 7.0)$ at $4{ }^{\circ} \mathrm{C}$. Concentrations of CPMV were obtained by UV spectroscopy at 260 $\mathrm{nm}$ using the molar extinction coefficient $\varepsilon_{\mathrm{CPMV}}=8.1 \mathrm{~mL} \mathrm{mg}^{-1} \mathrm{~cm}^{-1}$.

$\mathrm{Q} \beta$ Virus-like Particle Production. Bacteriophage $\mathrm{Q} \beta$ VLPs were expressed as previously reported. ${ }^{12,13}$ The gene encoding for $\mathrm{Q} \beta$ coat protein (CP) (NCBI accession: P03615) was codon optimized for BL21 E. coli expression and synthesized/cloned by GenScript Biotech Co. into pCDF_Q $\beta$. Pure $\mathrm{Q} \beta$ was resuspended in PBS $\mathrm{pH} 7.4$ and quantified using the total protein Pierce BCA assay kit (Thermo Fisher Scientific).

Antigen in Silico Characterization. Peptide antigens (B cell epitopes) from SARS-CoV-2 spike protein (accession ID: YP_009724390.1) were selected from previous reports ${ }^{24-28}$ and examined using an online peptide calculator (https://pepcalc.com/) to determine molecular weight and isoelectric point (pI) (Table 1).

CPMV and $\mathrm{Q} \boldsymbol{\beta}$ Vaccine Candidate Synthesis. B cell epitopes from SARS-CoV-2 spike protein (accession ID: YP_009724390.1) with an N-terminal cysteine residue and triple glycine linker (C-GGGpeptide) were obtained from GenScript Biotech Co. (Table 1). Peptides were conjugated to CPMV or $\mathrm{Q} \beta(\mathrm{CPMV} / \mathrm{Q} \beta)$ using a twostep bioconjugation method. ${ }^{10}$ First, solvent-exposed lysine residues on $\mathrm{CPMV} / \mathrm{Q} \beta$ were chemically modified with the (NHS)-activated ester 
moiety of a heterobifunctional linker $\mathrm{SM}(\mathrm{PEG})_{4}$ to form a CPMV/Q $\beta$ PEG-maleimide intermediate. Specifically, $4 \mathrm{mg}$ of $\mathrm{CPMV} / \mathrm{Q} \beta$ was reacted with $\mathrm{SM}(\mathrm{PEG})_{4}$ linker (3000 molar equiv) in a $1 \mathrm{~mL}$ reaction volume of $10 \mathrm{mM} \mathrm{KP}$ buffer ( $\mathrm{pH} 7.4$ ) for $2 \mathrm{~h}$ at room temperature. $\mathrm{CPMV} / \mathrm{Q} \beta$ intermediates were purified using Amicon Ultra- $0.5 \mathrm{~mL}$ centrifugal filters at $10000 \mathrm{~g}$ for $5 \mathrm{~min}$ and washed $3 \times$ using $10 \mathrm{mM} \mathrm{KP}$ buffer. Second, the N-terminal cysteine of the peptide epitopes was reacted with the maleimide groups displayed on the $\mathrm{CPMV} / \mathrm{Q} \beta$ intermediates to form the multivalent VNP-peptide conjugates. Specifically, $4 \mathrm{mg}$ of $\mathrm{CPMV} / \mathrm{Q} \beta$ intermediates was reacted with peptide (6000 molar equiv for CPMV and 700 molar equiv for $\mathrm{Q} \beta$ ) for $12 \mathrm{~h}$ at room temperature on a rotary inverter. The resulting CPMV/ $\mathrm{Q} \beta$-peptide conjugates were purified and pelleted by ultracentrifugation at $4{ }^{\circ} \mathrm{C}$ and $52000 \mathrm{~g}$ over a $30 \%(\mathrm{w} / \mathrm{v})$ sucrose cushion. Pellets were washed $3 \times$ and resuspended using $10 \mathrm{mM} \mathrm{KP}$ buffer. Finally, CPMV/ $\mathrm{Q} \beta$-peptide conjugates were then dialyzed overnight using a $30 \mathrm{kDa}$ dialysis membrane at $4{ }^{\circ} \mathrm{C}$ to ensure complete removal of excess reagents. Of note, conjugation of the following peptides $(106,153,454$, and 826) required modifications to standard bioconjugation protocol (briefly discussed below).

Due to insolubility in aqueous media, peptides 106, 153, and 454 required formulation by Pluronic F127 (poloxamer 407, SigmaAldrich). Briefly, each respective peptide was dissolved at $10 \mathrm{mg} / \mathrm{mL}$ concentration along with $10 \%(\mathrm{w} / \mathrm{w}) \mathrm{F} 127$ in DMSO, and the solution was transferred into a $1 \mathrm{kDa}$ molecular weight cutoff dialysis membrane (Spectra-Por, Spectrum Laboratories). Peptides were dialyzed against $10 \mathrm{mM} \mathrm{KP}$ buffer ( $\mathrm{pH} \mathrm{7.4)}$ ) for $2 \mathrm{~h}$ in a $1 \mathrm{~L}$ volume to promote F127 micellization and encapsulation of the hydrophobic peptide (buffer was exchanged at $30 \mathrm{~min}$ and $1 \mathrm{~h}$ ). Formulated peptides were then used in a bioconjugation reaction with F127-coated VNP intermediates (coating process described below). Of note, peptide 826 did not require formulation; however, it still required coated VNP intermediates. A 4 $\mathrm{mg}$ amount of $\mathrm{CPMV} / \mathrm{Q} \beta$-PEG-maleimide intermediate was first mixed with $4 \%(\mathrm{w} / \mathrm{w})$ F127 in $10 \mathrm{mM} \mathrm{KP}$ buffer and incubated on ice for $1 \mathrm{~min}$ followed by $10 \mathrm{~s}$ of vortexing. Next, the sample was equilibrated to room temperature for $5 \mathrm{~min}$ followed by $10 \mathrm{~s}$ of vortexing to induce $\mathrm{CPMV} / \mathrm{Q} \beta$ coating with F127. Finally, coated $\mathrm{CPMV} / \mathrm{Q} \beta$ intermediates were subject to reaction with peptides 106 , 153,454 , or 826 ( 3000 molar equiv for CPMV and 500 molar equiv for $\mathrm{Q} \beta$ ) for $12 \mathrm{~h}$ at room temperature on a rotary inverter. Purification was as described above.

CPMV and $\mathrm{Q} \beta$ Vaccine Candidate Characterization. To verify peptide conjugation, $10 \mu \mathrm{g}$ of $\mathrm{CPMV} / \mathrm{Q} \beta$ and purified $\mathrm{CPMV} / \mathrm{Q} \beta$ vaccine candidates were analyzed by sodium dodecyl sulfate polyacrylamide gel electrophoresis (SDS-PAGE) performed under reducing conditions on NuPAGE 4-12\% Bis-Tris protein gels (Thermo Fisher Scientific) and stained with GelCode Blue Safe protein stain (Thermo Fisher Scientific). The gel images were acquired using the ProteinSimple FluorChem R imaging system, and densitometry analysis (ImageJ 1.44o software, http://imagej.nih.gov/ ij) was used to quantify the number of peptides conjugated per CPMV/ $\mathrm{Q} \beta$. CPMV $/ \mathrm{Q} \beta$ integrity was confirmed by transmission electron microscopy (TEM) using a FEI Tecnai Spirit G2 Bio TWIN instrument following uranyl acetate staining. Particles were concentrated at 0.5 $\mathrm{mg} / \mathrm{mL}$ in $\mathrm{KP}$ buffer, and the size was corroborated by dynamic light scattering (DLS) using a Malvern Instruments Zetasizer Nano at $25^{\circ} \mathrm{C}$ in plastic disposable cuvettes.

Hot-Melt Extrusion to Formulate Trivalent $Q \beta / P L G A$ SlowRelease Implants. The poly(lactic-co-glycolic acid) (PLGA) implants were prepared using our previously reported desktop melt-processing system. ${ }^{12,13,29,30}$ In brief, a fine PLGA powder (Akina Inc. 50:50 LG ratio, MW $10-15 \mathrm{kDa}$ ) was prepared by passing through a -45 mesh (Sigma-Aldrich). The $\mathrm{Q} \beta$ vaccine candidates were individually lyophilized. To obtain a trivalent vaccine candidate, $\mathrm{Q} \beta 570, \mathrm{Q} \beta 636$, and $\mathrm{Q} \beta 826$ were mixed at equal ratio before hot melt-extrusion. Implant formulation was as follows: $80 \%$ PLGA, $10 \% \mathrm{Q} \beta$, and $10 \%$ PEG8000 (by weight). The dry components were mixed by vortexing and loaded into the hot melt-processing system. The barrel was heated to $70{ }^{\circ} \mathrm{C}$ for $90 \mathrm{~s}$, and the piston was set to $10 \mathrm{psi}(69 \mathrm{kPa})$ for extrusion.
Implants were dried and stored at room temperature with desiccants until further use.

Microneedle Formulation of Trivalent $Q \beta$ Vaccine Candidates. PDMS Microneedle Mold Fabrication. The procedure of fabrication of polydimethylsiloxane (PDMS) negative MN silicone molds was developed by casting a PDMS (86:14, base curing agent) solution (SYLGARD 184) onto a master MN acrylate mold array. Prior to casting, PDMS was degassed at $2500 \mathrm{rpm}$ for a period of $5 \mathrm{~min}$ within a closed desiccator connected to a vacuum pump running at 23 in $\mathrm{Hg}$ $(78 \mathrm{kPa})$. Silicone molds were left at room temperature overnight prior to demolding. Following the curing process, negative molds were demolded and custom resized by a blade cut. Prior to the MN fabrication, silicone molds were cleaned and triple washed with soap, ultrasonicated, sterilized at $80{ }^{\circ} \mathrm{C}$, and stored in a sealed container.

Dissolvable Microneedle Fabrication Process. Active MN $(3 \mathrm{Q} \beta$ $\mathrm{MN}$ active, trivalent candidate) patches were fabricated by following a micromolding procedure by employing negative $\mathrm{MN}$ silicon molds. Briefly, a volume of $50 \mu \mathrm{L}$ of a Mg microparticle (TangShanWeiHao Magnesium Powder Co., Ltd. China) 2-propanol solution $(50 \mathrm{mg} / \mathrm{mL})$ was poured onto negative $\mathrm{MN}$ molds to pack the cavities homogeneously. Subsequently, a volume of $250 \mu \mathrm{L}$ of a $10 \%(\mathrm{w} / \mathrm{v})$ polyvinylpyrrolidone (PVP, MW $=360 \mathrm{~K}$, Sigma-Aldrich) aqueous solution ( $\mathrm{pH} 11.5$ and $\mathrm{pH} 7$ ) was cast over silicone molds within a sealed desiccator at 23 in $\mathrm{Hg}(78 \mathrm{kPa})$ for a total time of $10 \mathrm{~min}$. Bubbles at the mold/interface were removed, and repetitive additions of polymer solution were casted until reaching a final volume of $750 \mu \mathrm{L}$. The corresponding payload ( $500 \mu \mathrm{g}$ of each $\mathrm{Q} \beta 570, \mathrm{Q} \beta 636$, and $\mathrm{Q} \beta 826)$ was incorporated onto the mold and allowed to dry for $48 \mathrm{~h}$ at room temperature within a sealed container. A transfer base adhesive (3M double-sided tape) was applied as the backing of the $\mathrm{MN}$ vaccine patch and further demolded from silicone templates. Passive $\mathrm{MN}(3 \mathrm{Q} \beta$ $\mathrm{MN}$ passive) patches were formulated by following the same protocol but without the incorporation of $\mathrm{Mg}$ microparticles. The corresponding active and passive $\mathrm{MN}$ patches were stored within a closed container at room temperature prior to use.

MN Patch Characterization. SEM images were obtained with the use of an FEI Quanta 250 ESEM instrument (Hillsboro, OR, USA). Prior to imaging, both active and passive $\mathrm{MN}$ patch samples were sputtered with iridium (Emitech K575X sputter coater), providing a fine grain metal deposition, and imaged with acceleration voltages of $2-$ $5 \mathrm{keV}$. Digital images of the vaccine $\mathrm{MN}$ patch (active and passive) were taken with a Sony a6000 digital camera coupled with a $55 \mathrm{~mm}$ Panagor 2.8 macro lens.

Immunization of Mice. All animal experiments were carried out in accordance with the Institutional Animal Care and Use Committee (IACUC) Office of the University of California, San Diego. Eight-weekold male Balb/c mice were purchased from Jackson Laboratory and kept under controlled conditions with chow and water ad libitum. For subcutaneous (s.c.) injection with liquid format, each CPMV or $\mathrm{Q} \beta$ vaccine candidate was concentrated at $1 \mathrm{mg} / \mathrm{mL}$ in PBS buffer (137 $\mathrm{mM} \mathrm{NaCl}, 2.7 \mathrm{mM} \mathrm{KCl}, 10 \mathrm{mM} \mathrm{Na}_{2} \mathrm{HPO}_{4}$, and $1.8 \mathrm{mM} \mathrm{KH}_{2} \mathrm{PO}_{4}, \mathrm{pH}$ $7.4)$, and $100 \mu \mathrm{L}$ was injected s.c. (100 $\mu \mathrm{g} /$ dose $)$ using a prime-boost protocol and injections carried out 2 weeks apart. For the trivalent in liquid format (s.c.) $\mathrm{Q} \beta 570, \mathrm{Q} \beta 636$, and $\mathrm{Q} \beta 826$ ( $3 \mathrm{Q} \beta$ s.c. group) each $\mathrm{Q} \beta$ vaccine candidate was concentrated at $3 \mathrm{mg} / \mathrm{mL}$ in $\mathrm{PBS}$, mixed 1:1:1 just prior to administration (100 $\mu$ L s.c. using $100 \mu \mathrm{g}$ of each vaccine candidate or $100 \mu \mathrm{g}$ in total) using the same prime-boost administration schedule. For immunization using the $Q \beta /$ PLGA slowrelease implants, a single-dose implant with $200 \mu$ g of each $\mathrm{Q} \beta$ vaccine candidate (to equate the $100 \mu \mathrm{g} /$ dose prime-boost s.c. injection) was administered using a $18 \mathrm{G}$ needle (BD Co.) s.c. behind the neck. Trivalent $\mathrm{Q} \beta \mathrm{MN}$ patches (either active or passive) were administered by pressing for $5 \mathrm{~min}$ against the naked skin, and then the patches were wrapped tight with tape overnight. MN patches were administered using the same prime-boost administration schedule. As control groups, $5 \mu \mathrm{g} /$ dose of the three free peptides $(570,636$, and 826 ; the dose was matched to the peptide dose delivered by the CPMV and $\mathrm{Q} \beta$ vaccine candidates), a blank implant (PLGA:PEG only), and blank MN (PVP only) were used. Five mice were assigned for each group. Blood was collected (in lithium-heparin-treated tubes (Thomas Scientific) by 
retroorbital bleeding before immunization (week 0 ) and then at weeks 2,4 , and 12 postimmunization. Plasma was collected by centrifugation at $2000 \mathrm{~g}$ for $10 \mathrm{~min}$ at room temperature and kept at $-80^{\circ} \mathrm{C}$ until use.

IgG Titers against Peptide and S Protein. The enzyme-linked immunosorbent assay (ELISA) was used to determine end point total IgG titers against the corresponding peptide epitope displayed in the CPMV or $\mathrm{Q} \beta$ vaccine candidates. The 96-well, maleimide-activated plates (Thermo Fisher Scientific) were prepared following the manufacturer's directions. In brief, the plates were coated with 100 $\mu \mathrm{L} /$ well of each peptide (same as used for conjugation) at $25 \mu \mathrm{g} / \mathrm{mL}$ in coating buffer $(0.1 \mathrm{M}$ sodium phosphate, $0.15 \mathrm{M}$ sodium chloride, 10 mM EDTA, $\mathrm{pH} 7.2)$ overnight at $4{ }^{\circ} \mathrm{C}$. Plates were washed three times using $200 \mu \mathrm{L} /$ well of PBST (PBS $+0.5 \%$ (v/v) Tween-20 (Thermo Scientific)) between every step. Plates were blocked for $1 \mathrm{~h}$ at room temperature using $200 \mu \mathrm{L} /$ well of $10 \mu \mathrm{g} / \mathrm{mL}$ L-cysteine (SigmaAldrich). After washing, 2-fold serial dilutions of plasma samples from immunized animals in coating buffer were added and incubated for $1 \mathrm{~h}$ at room temperature. After washing, an HRP-labeled goat anti-mouse IgG secondary antibody (Thermo Fisher Scientific) diluted 1:5,000 in PBST was added $(100 \mu \mathrm{L} /$ well $)$ and incubated for $1 \mathrm{~h}$ at room temperature. After a final washing step, 1-Step Ultra TMB substrate (3,3',5,5'-tetramethylbenzidine, Thermo Fisher Scientific) was added $(100 \mu \mathrm{L} /$ well $)$ and developed for $10 \mathrm{~min}$; the reaction was then stopped using $2 \mathrm{~N} \mathrm{H}_{2} \mathrm{SO}_{4}(100 \mu \mathrm{L} /$ well) (Thermo Scientific). The IgG titer against SARS-CoV-2 $S$ protein was determined as described above for peptide but using 96-well nickel activated plates (Thermo Fisher Scientific) coated with $200 \mathrm{ng}$ of His-tagged S protein per well (GenScript Biotech Co.). Plasma samples were diluted 1:1000 in PBS. The same secondary antibody dilution and substrate as above were used to develop the assay. The absorbance was read at $450 \mathrm{~nm}$ on a Tecan microplate reader. The end point antibody titers were defined as the reciprocal serum dilution at which the absorbance exceeded two times the background value (blank wells without plasma sample).

Antibody Isotyping. The ELISA was adapted from the protocol against peptide described above; instead of serial plasma dilutions, samples from week 4 (diluted 1:1000 in coating buffer) were tested. The secondary antibodies used were an HRP-labeled goat anti-mouse IgG1 (Invitrogen PA174421, 1:5000), IgG2a (Thermo Scientific A10685, 1:1000), IgG2b (Abcam ab97250, 1:5000), IgG2c (Abcam ab9168, 1:5000), IgG3 (Abcam ab98708, 1:5000), IgE (Invitrogen PA184764, 1:1000), and IgM (Abcam ab97230, 1:5000). The IgG2a/ IgG1 ratio was reported for each group, and a ratio higher than 1 was considered as Th1 response.

ELISpot Assay. A mouse IFN- $\gamma / \mathrm{IL}-4$ double-color ELISPOT kit (Cellular Technology Ltd.) was used. Briefly, 96-well ELISPOT plates were coated using an anti-mouse interferon-gamma (IFN- $\gamma$ ) capture antibody and anti-mouse interleukin-4 (IL-4) capture antibody overnight at $4{ }^{\circ} \mathrm{C}$ (both were used at a 1:166 dilution). Splenocyte suspensions collected from three mice after 2 or 10 weeks post immunization with each $\mathrm{Q} \beta$ vaccine candidate were analyzed and added to the plates $\left(1 \times 10^{6}\right.$ cells/well $)$ following stimulation with 100 $\mu \mathrm{L}$ of medium alone (negative control), free peptides $(20 \mu \mathrm{g} / \mathrm{mL})$ of each epitope, unmodified $\mathrm{Q} \beta(10 \mu \mathrm{g} / \mathrm{mL})$, or $50 \mathrm{ng} / \mathrm{mL}$ phorbol 12 myristate 13-acetate (PMA)/1 $\mu \mathrm{g} / \mathrm{mL}$ ionomycin (Sigma-Aldrich) (positive control) at $37{ }^{\circ} \mathrm{C}$ and $5 \% \mathrm{CO}_{2}$ for $24 \mathrm{~h}$. The plates were washed with PBST and the incubated with anti-murine IFN- $\gamma$ (FITClabeled, 1:1000 dilution) and anti-murine IL-4 (biotin-labeled, 1:666 dilution) antibodies for $2 \mathrm{~h}$ at RT. Plates were washed, and streptavidinalkaline phosphatase (AP, 1:1000 dilution) and anti-FITC-horseradish peroxidase secondary antibodies (HRP, 1:1000 dilution) were added to each well and incubated for $1 \mathrm{~h}$ at room temperature. Plates were washed with PBST and distilled water, then incubated with AP substrate for $15 \mathrm{~min}$ at room temperature, washed with distilled water, and incubated with HRP substrate for $10 \mathrm{~min}$ at room temperature. Plates were rinsed with water and air-dried at room temperature overnight. Colored spots were quantified using a Immunospot S6 Entry analyzer. The splenocytes were evaluated per animal and tested in triplicate for each stimulant.

SARS-CoV-2 Surrogate Virus Neutralization Test. The SARS$\mathrm{CoV}-2$ surrogate virus neutralization test (sVNT) kit (GenScript Co.) is a blocking ELISA that mimics the virus neutralization process. The kit contains two key components: an HRP-conjugated recombinant SARSCoV-2 RBD fragment (HRP-RBD) and a human ACE2 receptor protein (hACE2). The protein-protein interaction between HRPRBD and hACE2 can be blocked by neutralizing antibodies against SARS-CoV-2 RBD. The assay was performed following the manufacturer's directions. In brief, plasma samples were diluted 1:10 and then mixed 1:1 with an HRP-RBD solution and incubated at $37^{\circ} \mathrm{C}$ for $30 \mathrm{~min}$. The mixed solution was then added to precoated hACE2 plates and incubated at $37^{\circ} \mathrm{C}$ for $15 \mathrm{~min}$. Then the plate was washed four times, and a colorimetric signal was developed on incubating the plate with TMB (HRP substrate) for $15 \mathrm{~min}$ at room temperature. Then absorbance was read at $450 \mathrm{~nm}$. A positive and negative control were tested in the same way as the plasma samples. The results were presented as percentage of inhibition rate and were calculated as follows:

Inhibition $=(1-(\mathrm{OD}$ value of sample

(OD value of negative control)) $\times 100$

A cutoff value was set up according to \% inhibition of control plasma (CPMV, free peptide, blank implant, or blank MN), and plasma samples with inhibition values greater than cutoff values were considered as neutralizing.

Neutralization Assay with SARS-CoV-2. Reduction of the virusinduced cytopathic effect (primary CPE assay) ${ }^{31}$ was performed through the Preclinical Services offered by The National Institute of Allergy and Infectious Diseases (NIAID). SARS-CoV-2 strain USA WA1/2020 was used. Briefly, confluent or near-confluent cell culture monolayers of Vero 76 cells were prepared in 96-well disposable microplates the day before testing. Cells were maintained in MEM (Sigma-Aldrich) supplemented with $5 \%(\mathrm{v} / \mathrm{v})$ fetal bovine serum (FBS). For antiviral assays the same medium was used but with FBS reduced to $2 \%(\mathrm{v} / \mathrm{v})$ and supplemented with $50 \mu \mathrm{g} / \mathrm{mL}$ gentamicin. The pooled plasma samples (week 4 postimmunization) from each CPMV vaccine candidate and unmodified CPMV (negative control) were tested in 10-fold serial dilutions. Five microwells were used per dilution: three for infected cultures and two for uninfected toxicity cultures. Controls consisted of six wells that were infected and not treated (virus controls) and six that were untreated and uninfected (cell controls) on every plate. Plasma samples and virus were mixed (1:1 ratio) and incubated for $1 \mathrm{~h}$ at $37^{\circ} \mathrm{C}$ before being added to cells. After incubation, growth media was removed from the cells, and the plasma sample/SARS-CoV-2 was applied in a $0.1 \mathrm{~mL}$ volume to wells. SARSCoV-2, normally at $\sim 60 \mathrm{CCID}_{50}(50 \%$ cell culture infectious dose $)$ in $0.1 \mathrm{~mL}$ volume, was added to the wells designated for virus infection. Medium devoid of SARS-CoV-2 was placed in toxicity control wells and cell control wells. Plates were incubated at $37{ }^{\circ} \mathrm{C}$ with $5 \% \mathrm{CO}_{2}$ until marked CPE $(>80 \%)$ was observed in virus control wells. The plates were then stained with $0.011 \%(\mathrm{w} / \mathrm{v})$ neutral red for approximately $2 \mathrm{~h}$ at $37^{\circ} \mathrm{C}$ in a $5 \% \mathrm{CO}_{2}$ incubator. The neutral red medium was removed, and the cells were rinsed with PBS to remove residual dye. The PBS was completely removed, and the incorporated neutral red was eluted with $50 \%$ Sorensen's citrate buffer $/ 50 \%(\mathrm{v} / \mathrm{v}$ ) ethanol for at least $30 \mathrm{~min}$. Neutral red dye penetrates living cells; thus, the more intense the red color, the larger the number of viable cells present in the wells. The dye content in each well was quantified at $540 \mathrm{~nm}$ wavelength. The dye content in each set of wells is converted to a percentage of dye present in untreated control wells and normalized based on the virus control. The $50 \%$ effective $\left(\mathrm{EC}_{50}\right.$, virus-inhibitory) concentrations and $50 \%$ cytotoxic $\left(\mathrm{CC}_{50}\right.$, cell-inhibitory) concentrations are then calculated by regression analysis. The quotient of $\mathrm{CC}_{50}$ divided by $\mathrm{EC}_{50}$ gives the selectivity index (SI) value. Plasma samples showing SI values $\geq 10$ were considered neutralizing.

Statistical Analysis. Data are presented as the mean \pm SD. Single comparisons were made with unpaired, two-tailed $t$ tests using SPSS Statistics software or GraphPad Prism 6. $P$ values less than 0.5 were considered statistically significant with $95 \%$ confidence. Replicates per experiment are detailed in each method section or figure. 
A

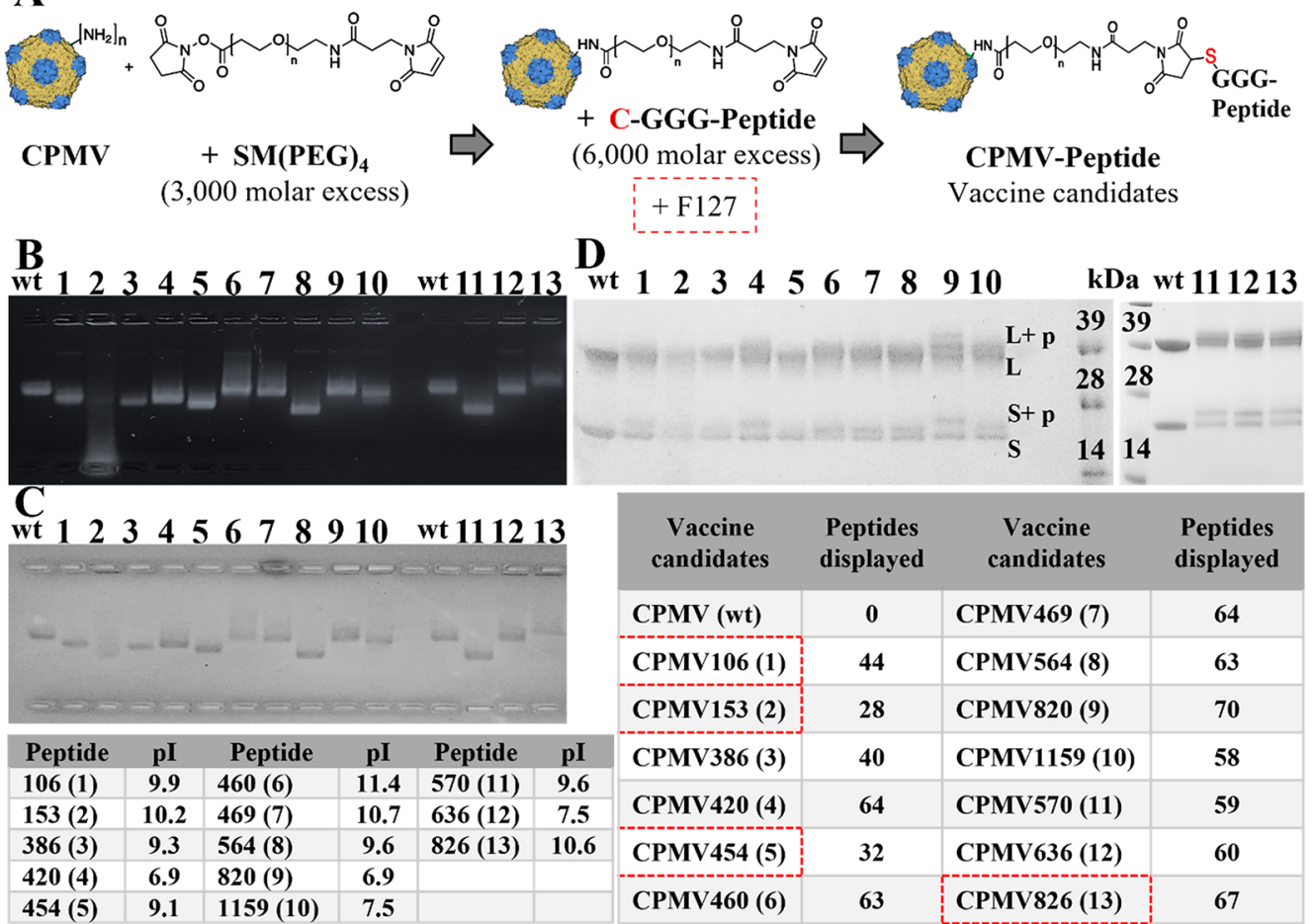

E

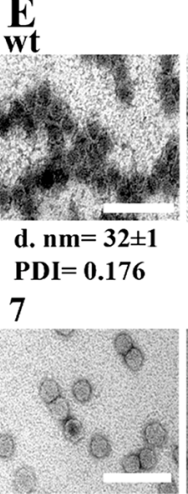

d. $n \mathrm{~m}=38 \pm 3$

$\mathrm{PDI}=\mathbf{0 . 2 2 1}$
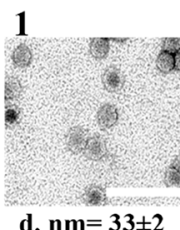

d. $\mathbf{n m}=33 \pm 2$
PDI $=0.055$

8

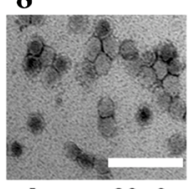

d. $\mathrm{nm}=39 \pm 2$

$\mathrm{PDI}=\mathbf{0 . 2 7 0}$
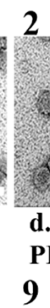

9

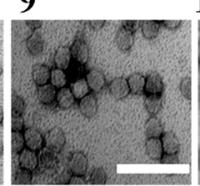

d. $n m=42 \pm 4$

$\mathrm{PDI}=\mathbf{0 . 1 3 1}$
3

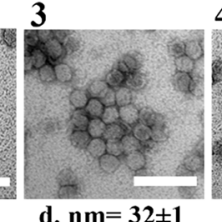

$\mathrm{PDI}=0.076$

10

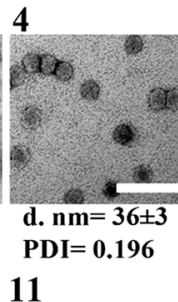

11

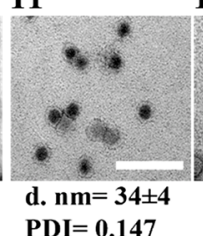

5

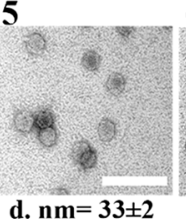

PDI $=0.132$

12

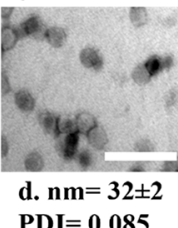

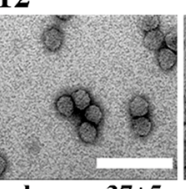

d. $\mathbf{n m}=37 \pm 5$

$\mathrm{PDI}=0.216$
6

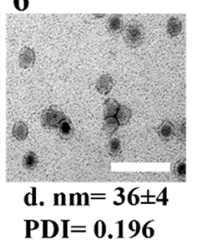

13

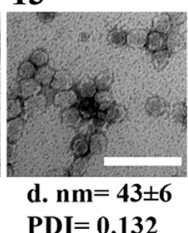

Figure 1. Synthesis and characterization of CPMV-based COVID-19 vaccine candidates. (A) Conjugation of B cell epitope peptides 106 (1), 153 (2), 386 (3), 420 (4), 454 (5), 460 (6), 469 (7), 564 (8), 820 (9), 1159 (10), 570 (11), 636 (12), and 826 (13) to CPMV. Agarose gel (0.8\%) stained with (B) GelRed (RNA) and (C) Coomassie blue (protein). The pI value from each peptide conjugated to each particle is shown in the table below the agarose gels. (D) SDS-PAGE: lane M, ladder. $S=$ small capsid protein; $S+$ pep = small capsid protein conjugated with peptide; $L=$ large capsid protein; $\mathrm{L}+$ pep $=$ large capsid protein conjugated with peptide. The number of peptides conjugated per particle $(\mathrm{S}+\mathrm{L}$ conjugated $)$ is reported in the table below the SDS-PAGE gel. Red dotted lines indicate the use of F127-assisted conjugation. (E) TEM images of negatively stained unmodified CPMV (wt) and CPMV-peptide conjugates (COVID-19 vaccine candidates). White bar $=100 \mathrm{~nm}$. Particle size was corroborated by DLS; $Z$-average $(d, \mathrm{~nm})$ and polydispersity index (PDI) value were established for each particle.

\section{RESULTS AND DISCUSSION}

Characterization of CPMV-Based Vaccine Candidates.

We selected 13 B cell epitopes (Table 1), which were identified from sera of patients who recovered from COVID-1924-27 or that were shown to be neutralizing when displayed on VLP technologies. ${ }^{27}$ We first considered the CPMV platform technology. CPMV can be engineered to display epitopes through genetic fusion ${ }^{32,33}$ or chemical conjugation; we opted for the latter because it provides a plug-and-play strategy particularly suitable for pandemic or epidemic responses. The CPMV capsid is formed by 60 identical copies of an asymmetric unit composed of a small (S, $24 \mathrm{kDa})$ and a large (L, $42 \mathrm{kDa})$ subunit. The $\mathrm{S}$ subunit folds into the A domain and $\mathrm{L}$ subunit into the B and C domain; CPMV exhibits pT3 symmetry. CPMV displays five addressable, solvent exposed amines from two Lys in the A domain, two Lys in the C domain, and one Lys in the B domain. These Lys side chains are chemically addressable but to different degrees. ${ }^{34}$ CPMV can be considered an adjuvant and display platform and could be stockpiled, and target epitopes could be conjugated as needed. The long-term stability of the platform and ease of vaccine manufacture allow for a rapid response to mutants (VOCs) or new emerging infectious diseases. We adapted previously published procedures ${ }^{10}$ and achieved conjugation of each of the 13 candidate $B$ cell epitopes using a two-step conjugation scheme (Figure 1A): first CPMV was conjugated with an $\mathrm{SM}(\mathrm{PEG})_{4}$ linker. The NHS 
A
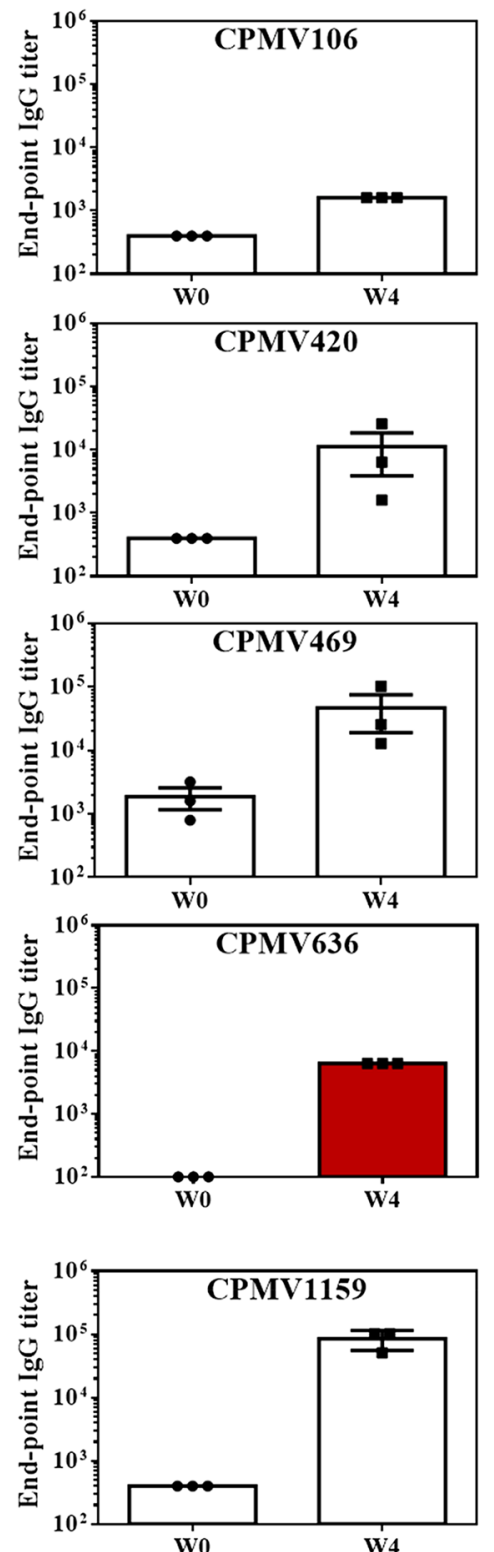
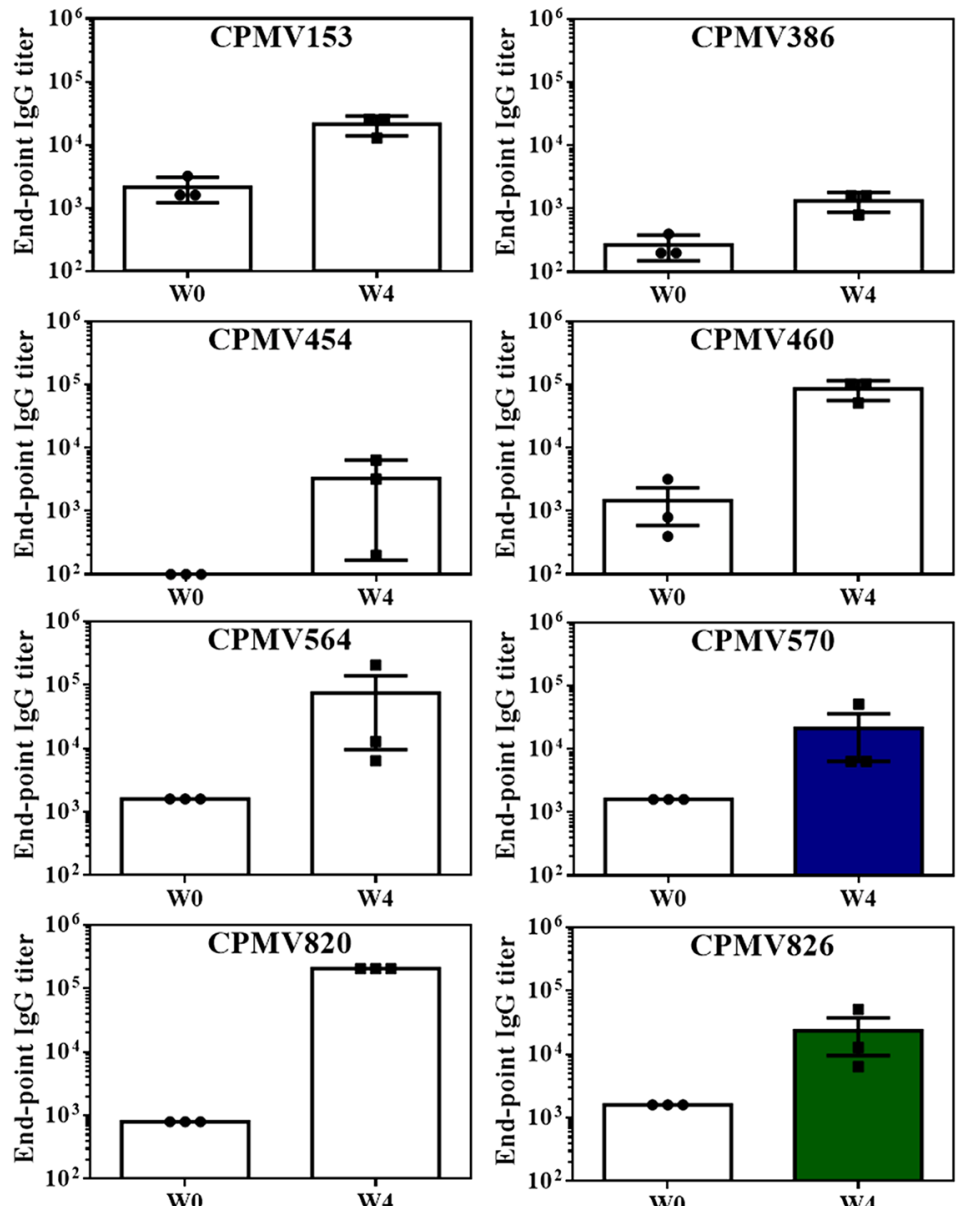

B

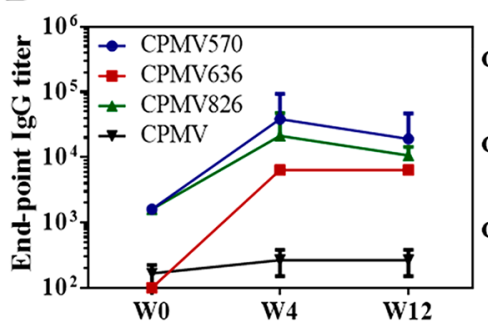

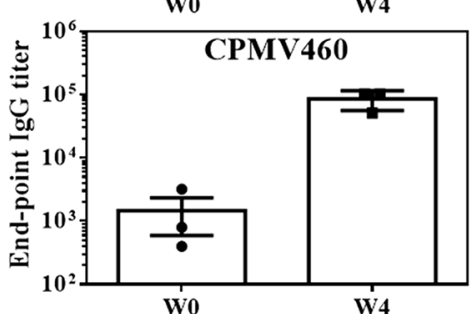
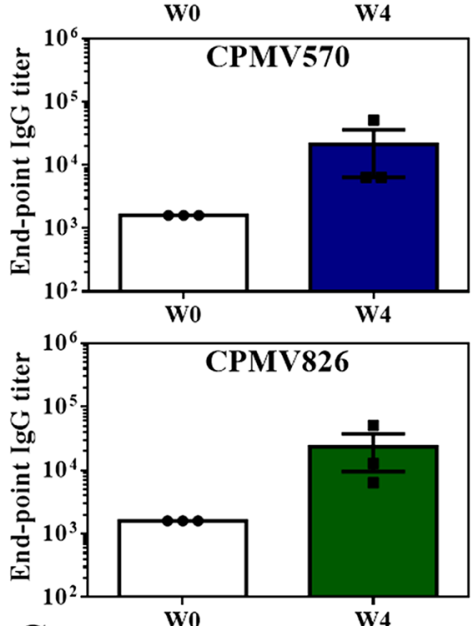

$\mathrm{C}$

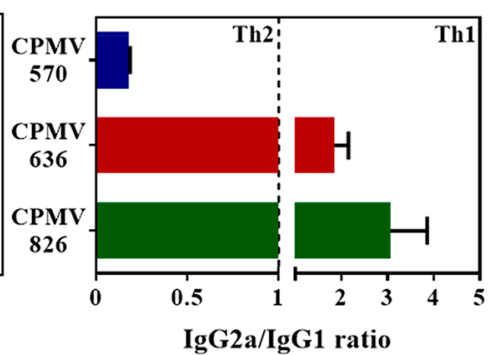

Figure 2. ELISA against the individual epitopes using plasma from immunized mice. (A) End point IgG titers after prime-boost administration of the various CPMV-based COVID19 vaccine candidates. All CPMV-based COVID19 vaccine candidates yielded epitope-specific IgG at 4 weeks postimmunization $(p<0.05$ vs prebleed). Three biological samples were tested individually $(n=3)$ from each group (mean and SD are shown). (B) IgG titers were determined at weeks 4 and 12 using plasma from mice vaccinated with CPMV570, CPMV636, and CPMV826 as well as native CPMV. (C) IgG subclass profile (IgG2a/IgG1 ratio) at week 4. A ratio of $<1$ was considered Th2-biased and $>1$ was considered as Th1-biased. Three biological samples were tested individually $(n=3)$ from each group (mean and SD are shown). Unpaired $t$ test (two-tailed, $95 \%$ confidence value) was used to compare between groups. $p$-Values $<0.05$ were considered statistically significant.

handle of the $\mathrm{SM}(\mathrm{PEG})_{4}$ linker reacts to solvent-exposed Lys side chains on $\mathrm{CPMV}^{34,35}$ and the introduced maleimide group is then coupled to the C-terminal Cys residue on the C-GGGpeptide sequence. Several peptides $(106,153,454$, and 826$)$ resulted in extensive aggregation; therefore a formulation approach in which a surfactant (Pluronic F127) was added to the reaction mix to stabilize the reagents was used. Postconjugation, the surfactant was removed and yielded stable conjugates (the detailed methods will be reported elsewhere). Resulting CPMV-based SARS-CoV-2 vaccine candidates were purified by ultracentrifugation and characterized using a combination of DLS, TEM, and gel electrophoresis (native agarose gels and denaturing SDS-PAGE) to confirm their structural integrity and degree of antigen incorporation (Figure 1, Table S1, Figure S1). DLS revealed the hydrodynamic diameter of the CPMV vaccine candidates with diameters ranging between 32 and $42 \mathrm{~nm}$ (Figure $1 \mathrm{E}$ and Figure S1). Overall, the size is in good agreement with the size of CPMV, 31 $\mathrm{nm}$ as reported based on its crystal structure. ${ }^{7}$ The significant increase in hydrodynamic diameter and wide range of sizes observed for the various CPMV formulations may be a property of the particular target epitope itself (e.g., charge, hydro- 
phobicity); this data may indicate some level of aggregation, neverthless, the particles were primarily monodisperse (see Figure 1). TEM imaging of negatively stained CPMV corroborated that particle preparation yielded monodisperse and intact CPMV nanoparticles measuring $\sim 31 \mathrm{~nm}$ in size (Figure 1E). Native agarose gels further validated the presence of intact CPMV (Figure 1B and C) with RNA and protein colocalizing after nucleic acid and protein staining. Of note however is CPMV153; while TEM imaging is consistent with intact nanoparticles being recovered after conjugation, native gel electrophoresis indicates partial loss of RNA (Figure 1B, lane 2). Changes in electrophoretic mobility of the CPMV formulations can be attributed to peptide conjugation; first conjugation of the peptides is targeting the Lys side chains, which reduces the overall positive charge on CPMV, leading to increased mobility toward the anode. Differences in mobility comparing the various COVID-19 vaccine candidates is explained by the varying charges of the peptide epitopes conjugated (Figure $1 \mathrm{~B}$ and $\mathrm{C}$; Table 1); the lower the IP, the higher the electrophoretic mobility. Lastly, SDS-PAGE analysis confirmed the presence of modified and unmodified small and large CP ( $\sim 24$ and $\sim 42$ $\mathrm{kDa}$ ) (Figure $1 \mathrm{D}$ ); the band analysis tool and ImageJ software indicate that peptide conjugation yielded $23 \%$ to $58 \%$ modification of the CPs, or in other words 27 to 70 peptides were displayed per CPMV (Table S1). Data indicate that intact CPMV-based COVID-19 vaccine candidates were successfully produced.

Immunogenicity and Neutralizing Activity of the CPMV-Based COVID-19 Vaccine Candidates. We first assessed the efficacy of the CPMV-based COVID-19 vaccine candidates using a prime-boost administration schedule (Figure $2 \mathrm{~A})$ with two doses (100 $\mu$ g each) 2 weeks apart applied s.c. All 13 candidates raised antibodies against their respective epitopes as observed using ELISA against the peptide epitopes (Figure 2). The end point antibody titers tested at week 4, 2 weeks after the prime-boost immunization, were more prominent in some candidates than others, with the highest levels observed for CPMV1159, CPMV820, and CPMV460 (end point IgG titers of $1: 85333,1: 204800$, and 1:85333, respectively; with increments of two or more magnitudes vs controls [1:400, 1:800, and $1: 1466$, respectively]); remaining candidates CPMV420, CPMV469, CPMV564, CPMV570, CPMV636, and CPMV826 had moderate titers (end point IgG titers of 1:11 200, 1:46 933, 1:74666, 1:38 400, 1:6400, and 1:23 466, respectively; with increments of at least 1 order of magnitude vs controls [1:400,1:1,866, 1:1,600,1:1,600,1:100, and 1:1,600, respectively]), except for CPMV106, CPMV153, CPMV386, and CPMV454, which showed only a modest level of response (end point IgG titers of 1:1600, 1:21 333, 1:1333, and 1:3266, respectively; with increments less than 1 order of magnitude vs controls [1:400, 1:2133, 1:266, and 1:100, respectively]) (Figure 2). The poor immunogenicity observed for the CPMV106, CPMV153, CPMV386, and CPMV454 may be explained by the number of the peptides conjugated, which were the lowest among all vaccines (Figure 1D; $<50$ peptides displayed per particle). Moreover, data indicate partial loss of RNA for CPMV153 (Figure 1B, lane 2), which may also explain its reduced immunogenicity; ssRNA is a known TLR7 agonist and thus expected to boost immunogenicity of the vaccine formulation.

We also selected three candidates (those that were found to be neutralizing, see below) for longitudinal study and found that the antibody titers were maintained over 12 weeks (Figure 2B).
Lastly, the plasma from the same three candidates (CPMV570, CPMV636, and CPMV826) were analyzed for antibody isotyping. Adaptative immunity response is mainly mediated by two main types of lymphocytes, $\mathrm{B}$ and $\mathrm{T}$ cells. Primed $\mathrm{T}$ helper (Th) cells, primarily Th1 and Th2 cells, and antigens activate B cells. Th1 cells secrete IFN- $\gamma$, which activates macrophages and induces the production of opsonizing antibodies (IgG2a/b) by B cells. The Th1 response primes cell-mediated immunity to protect against intracellular pathogens (e.g., viruses). On the other hand, Th2 cells secrete cytokines such as IL-4, which elicit B cells to produce neutralizing antibodies (IgG1). Th2 cells generally induce a humoral (antibody-based) response essential in the protection against extracellular pathogens and toxins. ${ }^{6}$ The complete Ig isotype profile is detailed in Figure S3D-F; Figure 2C shows the IgG2a/IgG1 ratio, which indicates a Th2 bias for CPMV570 and Th1 bias for CPMV636 and CPMV826. CPMV-based vaccines have been previously reported to induce Th1-biased responses (with IgG2a > IgG1 ratio > 1). ${ }^{4,10,40}$ Our data indicate that the epitope itself can influence the resulting immune response with only candidate 570 shifting toward a Th2 bias.

Next, we tested mouse plasma against the $S$ protein via ELISA and confirmed that IgG specific toward SARS-CoV-2 S protein was indeed raised (Figure 3A). Each candidate tested positive; however, CPMV1159 gave particularly high signals (consistent

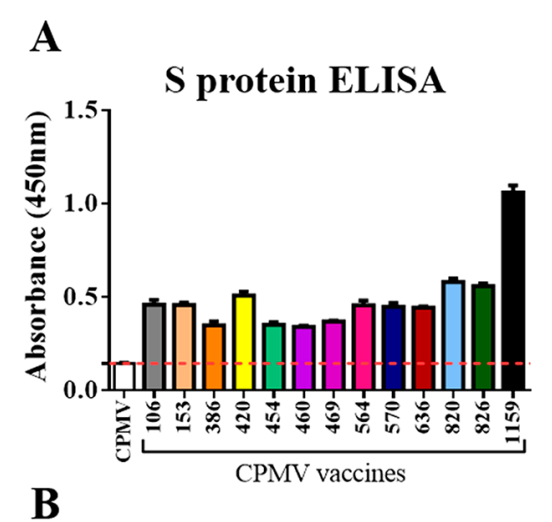

RBD-ACE2 blocking assay

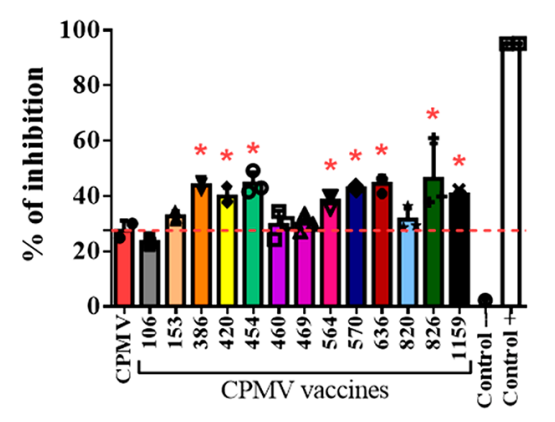

Figure 3. ELISA binding of IgG to SARS-CoV-2 $S$ protein. (A) Absorbance $(450 \mathrm{~nm})$ of plasma from animals vaccinated with the different CPMV vaccine candidates and unmodified CPMV as control. All groups were significantly higher than the CPMV control $(p<0.05)$. (B) Percentage of inhibition of plasma samples from week 4 against $S$ protein in vitro. The red dotted line represents the cutoff value, and any group above that value was considered neutralizing against the recombinant $S$ protein. $*=p<0.05$ vs unmodified CPMV control. Unpaired $t$ test (two-tailed, $95 \%$ confidence value) was used to compare between groups. $p$-Values $<0.05$ were considered statistically significant. 
Table 2. Neutralization Assay against SARS-CoV-2 in Vitro ${ }^{a}$

\begin{tabular}{|c|c|c|c|c|c|}
\hline \multirow[b]{2}{*}{ Plasma sample } & \multirow[b]{2}{*}{ Drug assay name } & \multicolumn{4}{|c|}{ SARS-CoV-2 } \\
\hline & & $\mathrm{EC}_{50}$ & $\mathrm{CC}_{50}$ & $\mathbf{S I}_{50}$ & Neu titer \\
\hline \multirow{2}{*}{ CPMV106 } & Visual & 59 & $>167$ & 2.8 & \multirow{2}{*}{120} \\
\hline & Neutral Red & 59 & $>167$ & 2.8 & \\
\hline \multirow{2}{*}{ CPMV153 } & Visual & 33 & $>167$ & 5.1 & \multirow{2}{*}{240} \\
\hline & Neutral Red & 17 & $>167$ & 9.8 & \\
\hline \multirow{2}{*}{ CPMV386 } & Visual & 17 & $>167$ & 9.8 & \multirow{2}{*}{480} \\
\hline & Neutral Red & 17 & $>167$ & 9.8 & \\
\hline \multirow{2}{*}{ CPMV420 } & Visual & 59 & $>167$ & 2.8 & \multirow{2}{*}{120} \\
\hline & Neutral Red & 58 & $>167$ & 2.9 & \\
\hline \multirow{2}{*}{ CPMV454 } & Visual & 59 & $>167$ & 2.8 & \multirow{2}{*}{120} \\
\hline & Neutral Red & 56 & $>167$ & 3 & \\
\hline \multirow{2}{*}{ CPMV460 } & Visual & 30 & $>167$ & 5.6 & \multirow{2}{*}{240} \\
\hline & Neutral Red & 26 & $>167$ & 6.4 & \\
\hline \multirow{2}{*}{ CPMV469 } & Visual & 59 & $>167$ & 2.8 & \multirow{2}{*}{120} \\
\hline & Neutral Red & 56 & $>167$ & 3 & \\
\hline \multirow{2}{*}{ CPMV564 } & Visual & 59 & $>167$ & 2.8 & \multirow{2}{*}{120} \\
\hline & Neutral Red & 51 & $>167$ & 3.3 & \\
\hline \multirow[b]{2}{*}{ CPMV570 } & Visual & 15 & $>167$ & 11 & \multirow[b]{2}{*}{480} \\
\hline & Neutral Red & 12 & $>167$ & 14 & \\
\hline \multirow[b]{2}{*}{ CPMV636 } & Visual & 15 & $>167$ & 11 & \multirow[b]{2}{*}{480} \\
\hline & Neutral Red & 13 & $>167$ & 13 & \\
\hline \multirow{2}{*}{ CPMV820 } & Visual & 59 & $>167$ & 2.8 & \multirow{2}{*}{120} \\
\hline & Neutral Red & 55 & $>167$ & 3 & \\
\hline \multirow[t]{2}{*}{ CPMV826 } & Visual & 7.4 & $>167$ & 23 & \multirow[t]{2}{*}{960} \\
\hline & Neutral Red & 6.3 & $>167$ & 27 & \\
\hline \multirow{2}{*}{ CPMV1159 } & Visual & 59 & $>167$ & 2.8 & \multirow{2}{*}{120} \\
\hline & Neutral Red & 51 & $>167$ & 3.3 & \\
\hline \multirow{2}{*}{ CPMV } & Visual & $>167$ & $>167$ & 0 & \multirow{2}{*}{$<60$} \\
\hline & Neutral Red & $>167$ & $>167$ & 0 & \\
\hline
\end{tabular}

${ }^{a} \mathrm{EC}_{50}=$ compound concentration $(\mu \mathrm{g} / \mathrm{mL})$ that reduces viral replication by $50 \% . \mathrm{CC}_{50}=$ compound concentration $(\mu \mathrm{g} / \mathrm{mL})$ that reduces cell viability by $50 \%$. $\mathrm{SI}_{50}=\mathrm{CC}_{50} / \mathrm{EC}_{50}$. $\mathrm{SI}_{50}$ values $\geq 10$ are considered as neutralizing. Neu titer $=$ neutralization titer at $\mathrm{EC}_{50}$. 


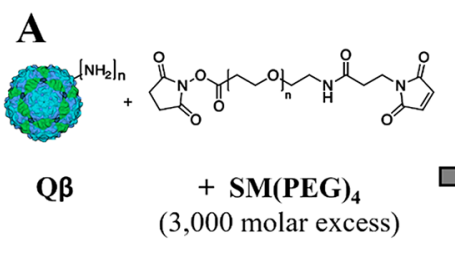

B

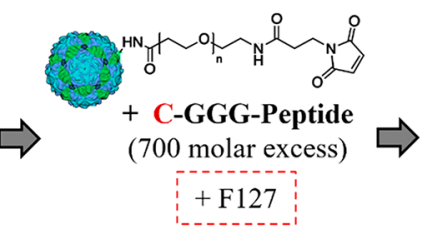

C

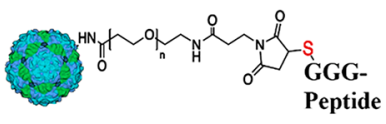

QB-peptide

Vaccine candidates
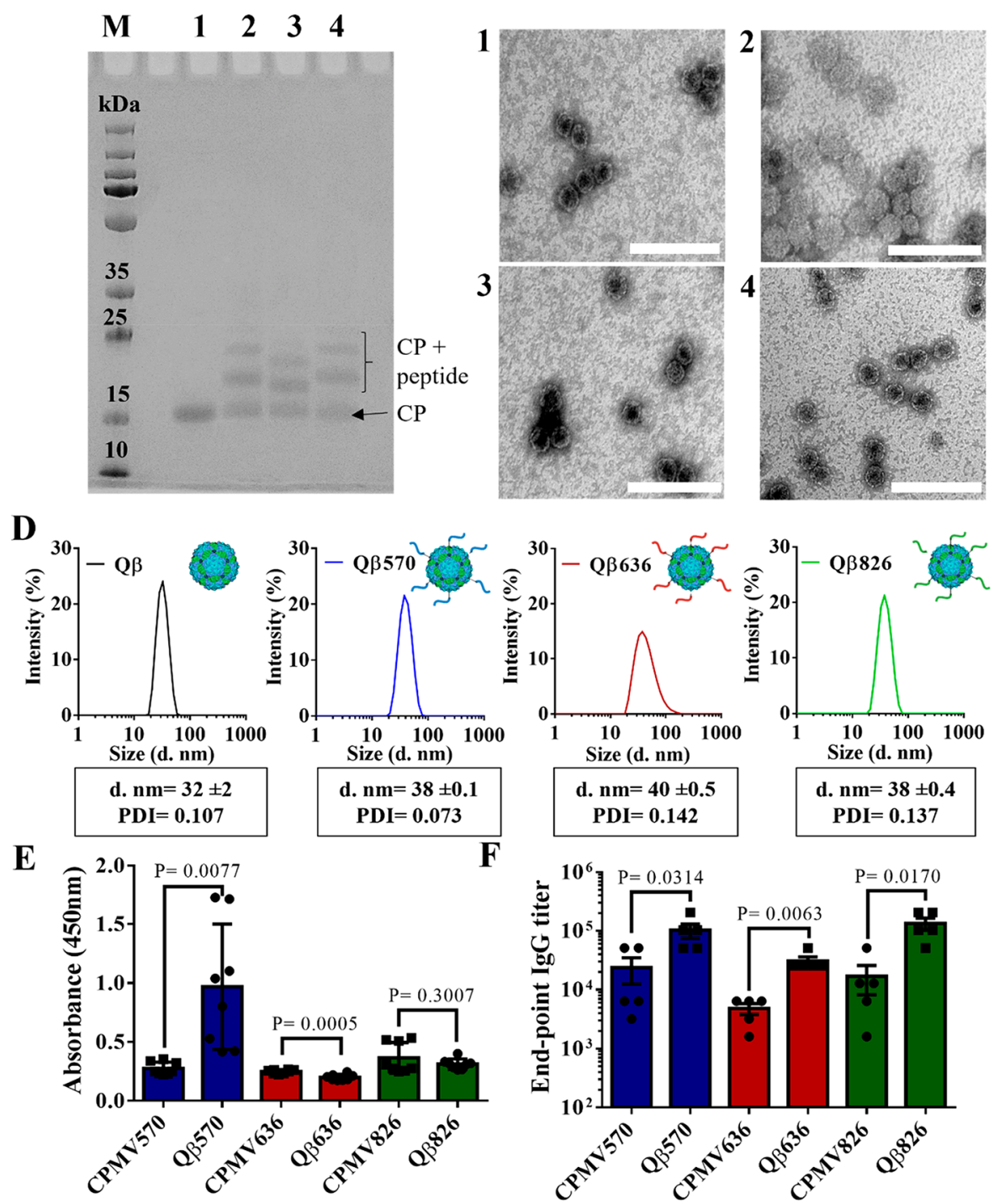

Figure 4. Synthesis and characterization of $\mathrm{Q} \beta$-based COVID-19 vaccine candidates. (A) Conjugation of $\mathrm{B}$ cell epitope peptides 570 (2), 636 (3), and 826 (4) to $\mathrm{Q} \beta$. (B) SDS-PAGE: lane M, ladder; CP, capsid protein alone or conjugated (CP + peptide) with a peptide. (C) TEM images of negatively stained unmodified $\mathrm{Q} \beta$ and $\mathrm{Q} \beta$-based vaccine candidates. Scale bar $=100 \mathrm{~nm}$. (D) Particle size determined by DLS; Z-average $(d$, nm) and polydispersity index (PDI) value were established for each particle. (E) ELISA against $S$ protein showing absorbance (450 nm) comparison side-byside of 570, 636, and 826 candidates from CPMV vs $\mathrm{Q} \beta$ vaccinated mice. Five biological samples were tested in duplicate $(n=10)$ from each group. (F) ELISA against corresponding peptides showing end point IgG titers compared side-by-side of 570, 636, and 826 candidates from CPMV vs Q $\beta$ vaccinated mice. Five biological samples were tested individually $(n=5)$ from each group. The unpaired $t$ test (two-tailed, $95 \%$ confidence value) was used to compared between groups. $p$-Values $<0.05$ were considered statistically significant.

with the peptide-based ELISA; see Figure 2). On the other hand, CPMV820, which gave high titers when probed against the peptide epitope, resulted in signals comparable to the other CPMV-based COVID19 vaccine candidates. Therefore, we found no direct correlation between the titers against the epitope vs $S$ protein, and this can be explained by the relative location and surface availability of the epitopes under the assay conditions.
To assay for SARS-CoV-2 neutralization, we used two assays: a SARS-CoV-2 surrogate virus neutralization test (sVNT) and a SARS-CoV-2 neutralization assay using Vero 76 cells. The sVNT is based on an RBD to ACE2 receptor binding assay and was used as a prescreening tool to select candidates with a neutralizing or inhibitory effect on the RBD-ACE2 interaction. Sera from eight of the 13 COVID-19 vaccine candidates demonstrated an inhibitory effect (Figure 3B) with subtle 
differences noted between the various constructs (negative controls, i.e., plasma from mice immunized with CPMV had no inhibitory effect on the RBD-to-ACE2 binding). Of note, while binding data indicate CPMV1154 to have increased interaction with $S$ protein compared to other candidates (Figure 3A), this did not correlate with increased inhibitory effect; the CPMV1154 inhibitory effect was comparable to other candidates tested.

All 13 candidates were subjected to a SARS-CoV-2 neutralization assay using SARS-CoV-2 strain USA_WA1/ 2020 and Vero 76 cells. Data indicate three candidates (CPMV570, CPMV636, and CPMV826; Table 2) to be neutralizing for SARS-CoV-2; these candidates were also inhibitory using the sVNT. In addition, candidates CPMV153 and CPMV386 were close to the cutoff with $\mathrm{IC}_{50}$ values of 9.8 ( $>10$ is considered neutralizing). Most striking are the high neutralizing titers achieved, especially for the CPMV826 candidate, which reached a neutralization titer (neu titer) of 960. This is comparable to titers reported in neutralization assays using Moderna's mRNA-1273 vaccine. ${ }^{36}$ Interestingly, CPMV153 and CPMV386 showed the lowest peptide display per particle (Figure 1D) but still exhibited similar neu titers (240 and 480, respectively) compared to CPMV570 and CPMV636. Nevertheless, the conjugation of the 153 and 386 peptides was extremely challenging; therefore, we continued only with 570 , 636 , and 826 peptides. Of note, the CPMV-based B cell epitope vaccine candidates outperformed neu titers reported using other VLP display strategies. We found that three candidates neutralized SARS-CoV-2 with neu titers of 480 for candidates CPMV570 and CPMV636 and a neu titer of 960 for candidate CPMV826, and this was achieved without addition of any adjuvants. In contrast, $B$ cell epitopes of SARS-CoV-2 S presented on hepatitis $B$ core protein $(\mathrm{HBc})$ particles adjuvanted with Alum yielded neu titers of only $80 .^{27}$ Interestingly though, the B cell epitopes 106, 153, 420, 454, and 469 that produced neutralizing antibodies when presented on $\mathrm{HBc}$ particles, albeit at low titers (inhibition of SARS-CoV-2 pseudovirus was reported at rates of $40-50 \%$ at 1:20 dilution), ${ }^{27}$ did not yield neutralizing responses when displayed using CPMV. Nevertheless, higher dosing or adding the Alum adjuvant may also yield comparable responses.

Validation of the Three Candidate Epitopes (570, 636, 826) Using the $Q \beta$ VLP Platform Technology. Only some but not all of the 13 epitope candidates produced neutralizing SARS-CoV-2 titers. Peptide epitopes that yielded neutralizing responses were epitopes 570,636 , and 826 , and these were identified from convalescent patients' sera. ${ }^{25,26}$ To further validate these epitopes, we tested whether the epitopes could be transferred to another platform, specifically using the VLPs from bacteriophage $\mathrm{Q} \beta$. $\mathrm{Q} \beta$ VLPs have been widely used as a vaccine platform. Because the $\mathrm{Q} \beta$ VLPs can be produced using bacterial expression (an industry standard for production of biologics) as opposed to molecular farming of CPMV-the $\mathrm{Q} \beta$-based vaccine candidates may offer a platform more readily translated into cGMP manufacturing for clinical testing. In fact, several $\mathrm{Q} \beta$ based vaccine candidates targeting chronic diseases have undergone or are undergoing clinical testing. ${ }^{5,6,11} \mathrm{Q} \beta$ VLPs were produced through expression in E. coli and then chemically modified with the selected peptide epitopes 570, 636, and 826 using chemical conjugation protocols as established for CPMV (Figure 4A). Also, for the characterization, we followed the procedures described for CPMV. SDS-PAGE analysis confirmed the presence of unmodified $\mathrm{Q} \beta \mathrm{CP}(\sim 14 \mathrm{kDa})$ and peptide- modified $\mathrm{Q} \beta$ CPs. The band pattern indicates that up to three peptides were conjugated per CP (Figure 4B), and this is in agreement with up to four available amines per $\mathrm{Q} \beta \mathrm{CP}$ (three from solvent-exposed Lys side chains and the N-terminus). ${ }^{37-39}$ Band density analysis was performed to estimate the degree of modification, and we determined $54 \%, 59 \%$, and $58 \%$ of the CPs of $\mathrm{Q} \beta 570, \mathrm{Q} \beta 636$, and $\mathrm{Q} \beta 826$, respectively, were modified with their respective peptide epitope. This equates to 98 to 107 peptides per $\mathrm{Q} \beta$ particle (each $\mathrm{Q} \beta$ VLP is composed of 180 identical copies of a CP unit, Table S1). TEM and DLS data confirmed the presence of monodisperse nanoparticles; broken particles or aggregation was not apparent (Figure 4C,D). DLS measurements indicated a significant increase in the hydrodynamic diameter from $32 \mathrm{~nm}$ for unmodified $\mathrm{Q} \beta$ to 38,40 , and $38 \mathrm{~nm}$ for the $\mathrm{Q} \beta 570, \mathrm{Q} \beta 636$, and $\mathrm{Q} \beta 826$ formulations. A profound increase in hydrodynamic diameter was also apparent for some of the CPMV-based vaccine candidates (see Figure 1), and this has also been documented for $\mathrm{HBc}$ particles displaying epitopes from SARS-CoV-2 S protein. ${ }^{27}$ This "swelling effect" may be even more profound for $\mathrm{Q} \beta$ vs CPMV, because the density of peptides displayed for $\mathrm{Q} \beta$ was higher compared to CPMV (Table S1). The increase in size as measured by DLS may be indication of aggregation, nevertheless the particles were primarily monodisperse. Overall data indicated that intact $\mathrm{Q} \beta$ based COVID-19 vaccine candidates $\mathrm{Q} \beta 570, \mathrm{Q} \beta 636$, and $\mathrm{Q} \beta 826$ were produced. We used a prime-boost schedule to immunize mice and confirmed that the peptide epitopes maintained their immunogenicity when presented on $\mathrm{Q} \beta$, yielding high epitope- and S-protein-specific antibodies (Figure $4 \mathrm{E}$ and $\mathrm{F}$ ). For the ELISA against $\mathrm{S}$ protein, the $\mathrm{Q} \beta 570$ vaccine candidate gave rise to higher antibody titers (3 times higher absorbance) compared to CPMV570; for the 636 formulation there was a trend with $\mathrm{Q} \beta 636$ producing increased antibody titers vs CPMV636; for $\mathrm{Q} \beta 826$ and CPMV826 there was no difference (Figure 4E). When testing the sera against the immobilized peptide, $\mathrm{Q} \beta$-based vaccine candidates $(\mathrm{Q} \beta 570$, $\mathrm{Q} \beta 636$, and $\mathrm{Q} \beta 826$ ) were higher (up to 1 log order of magnitude) vs CPMV570, CPMV636, and CPMV826, respectively (Figure $4 \mathrm{~F}$ ). This may be explained with the higher payload delivery of $\mathrm{Q} \beta$, which displayed up to twice the number of peptides compared to CPMV (Table S1); this is consistent with reports demonstrating that highly ordered repetitive arrays of epitopes are effective for the induction of immune responses and breaking B cell tolerance. ${ }^{5,6}$ Nevertheless, data indicate $\mathrm{CPMV}$ and $\mathrm{Q} \beta$ to be suitable platforms for peptide display; here we chose to move forward with the $\mathrm{Q} \beta$-based platform to produce mono- and trivalent COVID-19 formulations that were delivered as soluble injections as well as slow-release implants and via microneedle patches.

Trivalent $\mathrm{Q} \beta$-Based COVID-19 Formulations and Their Delivery Devices. In previous work focused on human papilloma virus (HPV) $)^{13}$ and cardiovascular vaccine candidates targeting key regulators of cholesterol levels, ${ }^{12}$ we established protocols for hot-melt extrusion protocols yielding degradable PLGA: $Q \beta$ implants that released the candidate vaccines over a $\sim 1$ month time frame after s.c. administration in mice. A combination of in vitro, ex vivo, and in vivo assays demonstrated that the released $\mathrm{Q} \beta$-based vaccine candidates remained structurally sound and biologically active. Building on this data, in this work we formulated a trivalent $\mathrm{Q} \beta$-based COVID19 vaccine candidate to be delivered as a single dose using a degradable PLGA: $Q \beta$ implant formulated with $80 \%$ PLGA (50:50 LG ratio), 10\% PEG8000, and $10 \%$ trivalent $\mathrm{Q} \beta$ vaccine 


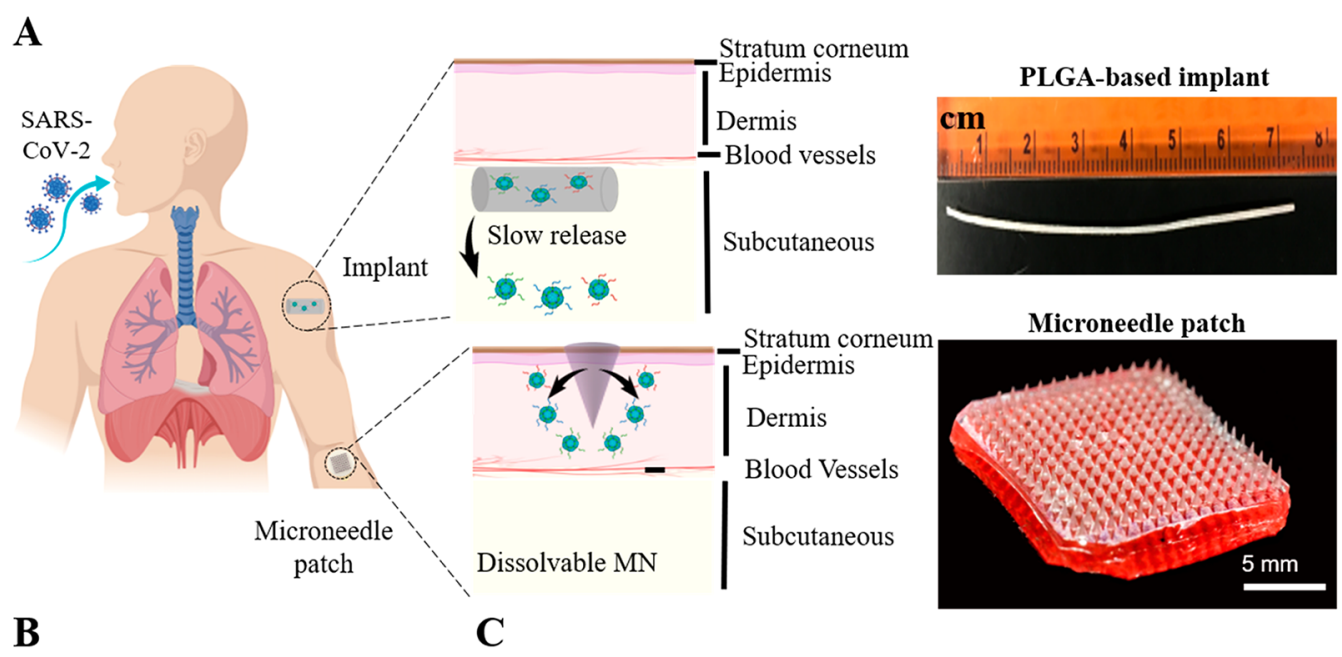

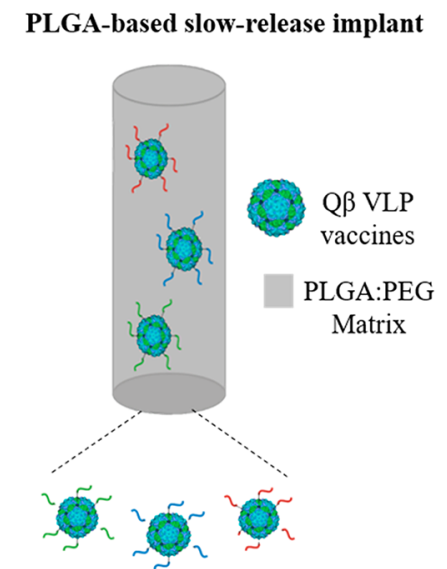

Trivalent $\mathrm{Q} \beta$ COVID-19 vaccine

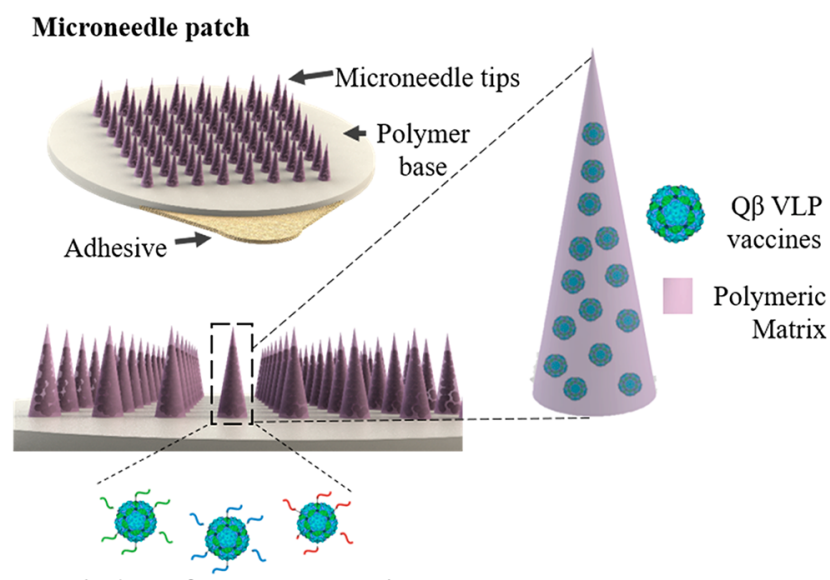

Trivalent $\mathrm{Q} \beta$ COVID-19 vaccine

Figure 5. Trivalent $\mathrm{Q} \beta$ COVID-19 vaccine candidate delivery strategies. (A) Concept of implant application s.c. highlighting the sustained and slow release and passive $\mathrm{MN}$ patches showing the release of the vaccine after the MN dissolves in the dermis. Position of the devices in the arm are for illustration only. Photographs of an implant and a MN patch are shown. Detailed description of the PLGA-based implant (B) and MN patch (C) with the trivalent $\mathrm{Q} \beta$ COVID-19 vaccine $(\mathrm{Q} \beta 570, \mathrm{Q} \beta 636$, and $\mathrm{Q} \beta 826)$.

( $\mathrm{Q} \beta 570, \mathrm{Q} \beta 636$, and $\mathrm{Q} \beta 826)$ (by weight). The trivalent vaccine candidate was obtained by mixing $\mathrm{Q} \beta 570, \mathrm{Q} \beta 636$, and $\mathrm{Q} \beta 826$ at equivalent weight percentages. After mixing all the components the melt-extrusion was performed and a solid and uniform rodshape $(0.5 \mathrm{~mm} \times 70 \mathrm{~mm})$ implant was generated (Figure 5A,B). The slow-release formulation and soluble version of the trivalent $\mathrm{Q} \beta 570, \mathrm{Q} \beta 636$, and $\mathrm{Q} \beta 826$ vaccine candidates were compared to monovalent formulations. In addition, we formulated the trivalent $\mathrm{Q} \beta$-based COVID-19 ( $\mathrm{Q} \beta 570, \mathrm{Q} \beta 636$, and $\mathrm{Q} \beta 826)$ vaccine candidates as a $M N$ patch by casting mixtures of $\mathrm{Q} \beta 570$, $\mathrm{Q} \beta 636$, and $\mathrm{Q} \beta 826$ and PVP into silicon molds. Two designs were employed, passive and active, where the latter contains $\mathrm{Mg}$ microparticles to enable micromixing to provide a propulsive force to improve the distribution of the payload from the device. While significant improvement in efficacy comparing the active vs passive MN delivery technology was previously demonstrated for cancer immunotherapy delivered directly into dermal melanomas, ${ }^{14,41}$ active dermal delivery of the vaccine candidates conferred no enhanced efficacy over the traditional (passive) MN patch (see below and Supporting Information). Therefore, in the following we focus on the comparison of the following delivery strategies: "passive" or traditional MN vs implant vs hypodermic injection using the mono- or trivalent vaccine candidates ( $\mathrm{Q} \beta 570, \mathrm{Q} \beta 636$, and $\mathrm{Q} \beta 826)$. The patch dimen- sions were designed to be $1.2 \mathrm{~cm} \times 1.2 \mathrm{~cm}$, and the array comprised 225 conical-shaped $\mathrm{MNs}(850 \mu \mathrm{m}$ in height and diameter of $400 \mu \mathrm{m}$; Figure S2). Characterization of the MN arrays by scanning electron microscopy (SEM) and corresponding energy dispersive X-ray elemental analysis (EDX) verified the structural integrity of $\mathrm{MN}$ structures in the array, both displaying tip sharpness and size reproducibility (Figure 5A,C and Figure S2). Previously made MN arrays made from PVP from our group have demonstrated the necessary mechanical stability and strength requirements for efficient patch application. ${ }^{14,41}$ The MN patches were designed to dissolve upon contact with the skin; as MNs breach dermal barriers and remain embedded within the application area, the polymer rapidly dissolves, ${ }^{14,41}$ therefore releasing $\mathrm{Q} \beta 570, \mathrm{Q} \beta 636$, and $\mathrm{Q} \beta 826$ simultaneously. The MN fabrication (materials, process, and design aspect) was carefully optimized to retain antigenicity without the need of using high temperatures or harsh organic solvents, thus transiently delivering the vaccines without leaving any sharp-based waste after application. After fabrication, both MN patch modalities demonstrated to be stable at room temperature and dry conditions for up to 1 month.

Immunogenicity of Trivalent $\mathbf{Q} \boldsymbol{\beta}$ Vaccine Candidates. Next, we established whether immunization using single-antigen formulations $(\mathrm{Q} \beta 570, \mathrm{Q} \beta 636$, or $\mathrm{Q} \beta 826)$ vs the trivalent $\mathrm{Q} \beta$ 


\section{A}

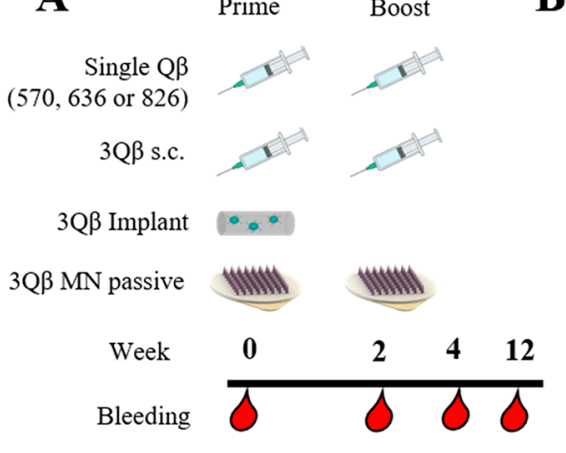

C
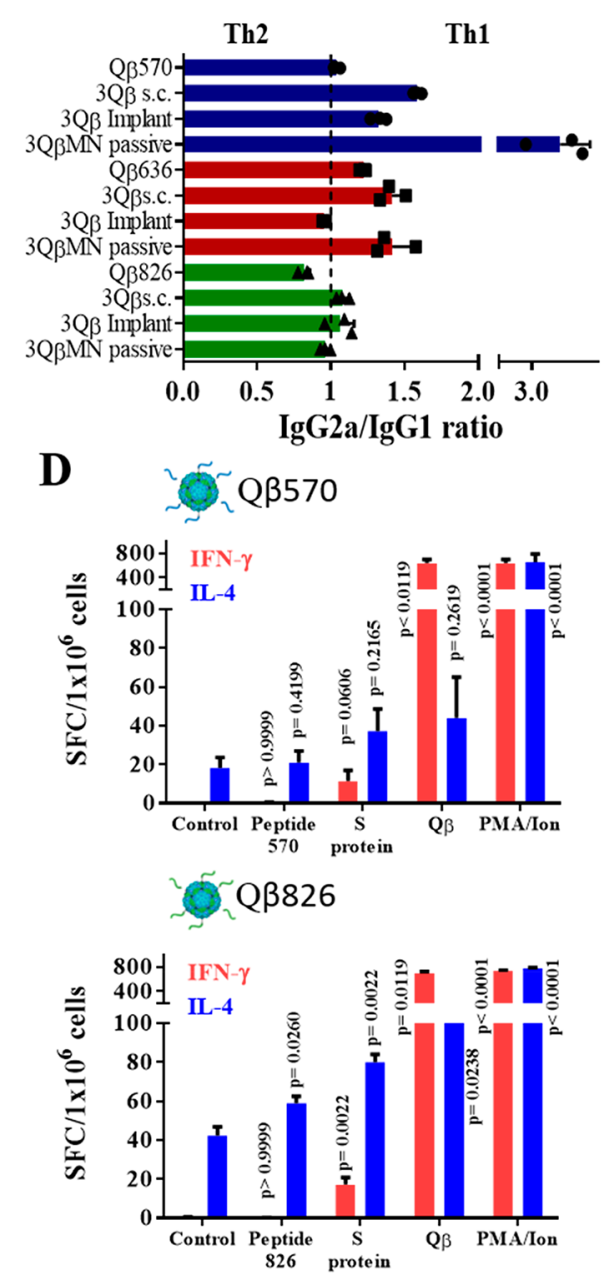

B
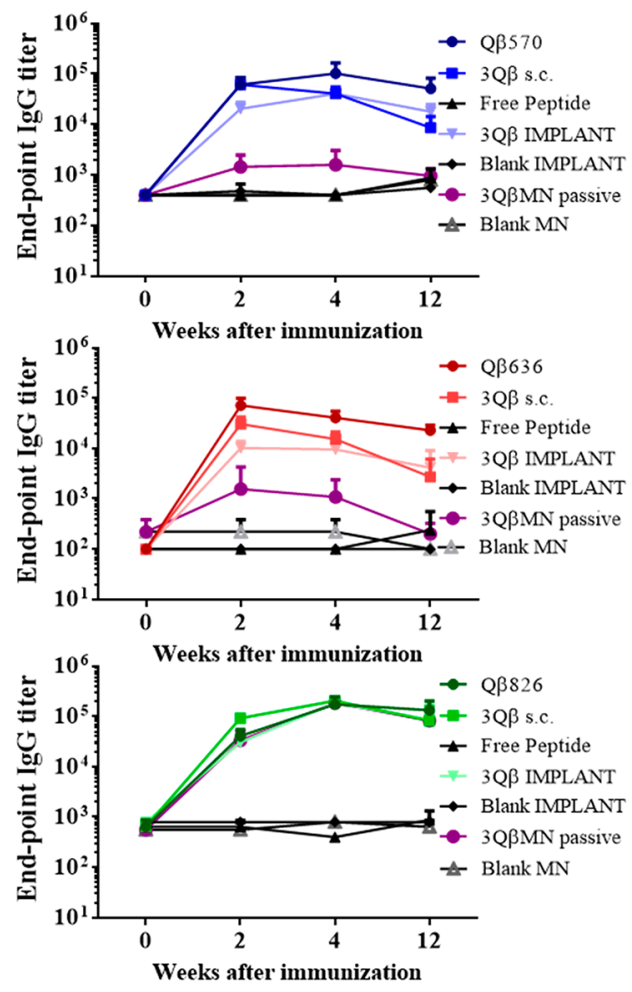

Q $\beta 636$
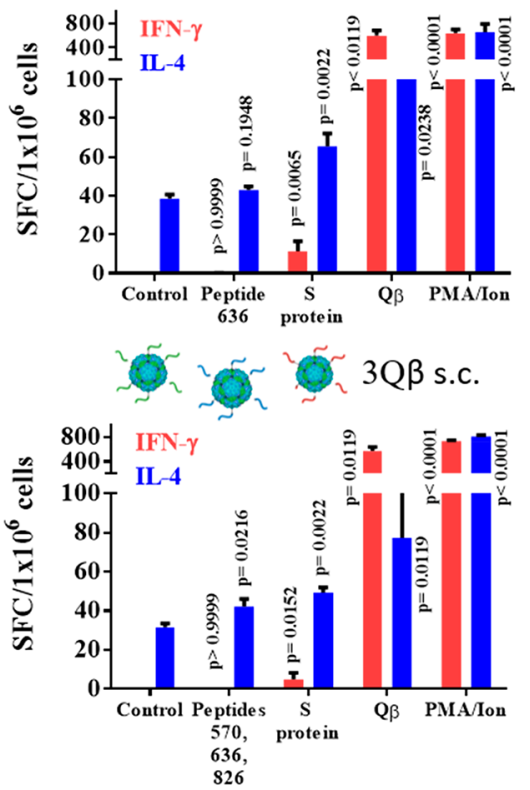

Figure 6. ELISA of sera against peptide. (A) Immunization schedule. The groups were studied as follows: each $\mathrm{Q} \beta$ vaccine alone (100 $\mu \mathrm{g}$ of single $\mathrm{Q} \beta$ / dose), trivalent s.c. ( $3 \mathrm{Q} \beta$ s.c., $100 \mu \mathrm{g}$ of each $\mathrm{Q} \beta$ /dose), trivalent implant $(3 \mathrm{Q} \beta$ implant, a single dose of $200 \mu \mathrm{g}$ of each $\mathrm{Q} \beta$ ), trivalent $\mathrm{MN}$ (passive, 50 $\mu \mathrm{g}$ of each $\mathrm{Q} \beta /$ dose). As control groups free peptide, blank implant, and blank MN were used, $n=5$ mice per group. (B) ELISA against the corresponding peptide (top $=570$; middle $=636$; bottom $=826$ ) showing end point IgG titers from vaccinated animals at different weeks $(0-12)$ after the first immunization. Week 0 corresponds to plasma collected prior to the first immunization. (C) ELISA against the corresponding peptide $($ blue $=$ 570 ; red $=636$; green $=826)$ showing IgG isotype profile $(\operatorname{IgG2a} / \operatorname{IgG1}$ ratio $)$ at week 4 ; a ratio of $>1$ was considered as Th1-biased and $<1$ as Th2biased. (D) T cell activation by the ELISpot assay. Splenocytes $\left(1 \times 10^{6}\right.$ cells per well) from immunized mice with $\mathrm{Q} \beta 570 ; \mathrm{Q} \beta 636 ; \mathrm{Q} \beta 826 ; 3 \mathrm{Q} \beta$ s.c. were stimulated with medium only (no stimulation control), single free peptide $(570,636,826)$ or a mixture (peptides $570+636+826)$, recombinant SARS-CoV-2 S protein, unmodified $\mathrm{Q} \beta$, or PMA/ionomycin (positive control). Cytokine (IFN- $\gamma$ and IL-4)-producing cells were counted as splenocyte-forming colonies (SFC). Splenocytes from three mice were tested in duplicate for each stimulation $(n=6)$. Data are represented as mean \pm SD. Mann-Whitney test (two-tailed, $95 \%$ confidence value) was used to compare against the control (medium only). $p$-Values $<0.05$ were considered statistically significant. 
vaccine candidate would yield desired antibody responses against peptide epitopes (Figure 6) and SARS-CoV-2 S protein (see Figure 7 ). The vaccine candidates were delivered by (i)
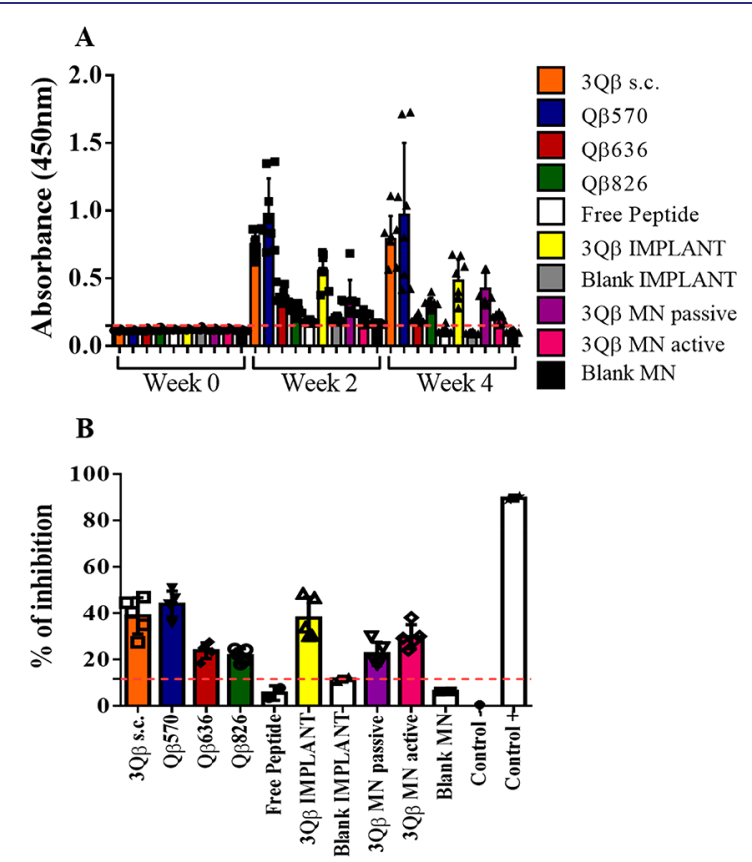

Figure 7. Sera from $\mathrm{Q} \beta$ vaccine groups analyzed by ELISA against SARS-CoV-2 $S$ protein and sVNT assay. (A) Absorbance (450 nm) of sera from animals vaccinated with the different $\mathrm{Q} \beta$ vaccine strategies and their corresponding controls. All groups were significantly higher at week 2 and 4 as compared to their controls $(p<0.05)$. Five biological samples were tested in duplicate $(n=10)$ from each group. Red dotted line represents the background signal from control groups. (B) Percentage of inhibition of plasma samples from week 4 against HRP-RBD in vitro (sVNT assay). The red dotted line represents the cutoff value; any group above that value was considered neutralizing against the recombinant $\mathrm{S}$ protein. ${ }^{*}=p<0.05$ vs control groups (free peptide, blank implant, and blank MN). Five biological samples were tested individually $(n=5)$ from each group. Control - and control + are internal controls for the technique and are PBS and ACE2 inhibitors, respectively.

injection s.c., (ii) injectable slow-release implant, or (iii) $\mathrm{MN}$ patches. The injections and $\mathrm{MN}$ delivery followed a prime-boost schedule, while the PLGA/Q $\beta$ blends were administered as a single dose; the implants are injectable and are placed s.c. (Figure 6A). In the previous work, we demonstrated that this particular formulation (80\% PLGA, $10 \% \mathrm{Q} \beta$, and $10 \%$ PEG8000 (by weight)) releases $\mathrm{Q} \beta$ from the implants over a time course of 30 days. $^{12,13,29,30}$ The sustained release alleviates the need for repeated dosing. Overall, we found that monovalent and trivalent vaccine candidates yielded comparable antibody titers against their target antigen (Figure 6B); this is consistent with our previous work on multivalent vaccine mixtures. ${ }^{12}$ Primeboost administration of soluble vaccine candidates (single antigen vs trivalent $3 \mathrm{Q} \beta$ groups) and single administration of the slow-release implant yielded comparable antibody titers against each antigen tested (Figure 6B; Figure S3A,B), demonstrating that single-dose administration of the PLGA/3Q $\beta$ is sufficient. With the $3 \mathrm{Q} \beta \mathrm{MN}$ group, reduced titers against the target epitope 570 and 636 were noted; however, the antibody titers against peptide epitope 826 were comparable to any other group tested (Figure 6B; Figure S3B).
While soluble and implant-based vaccine candidates were delivered s.c., the MN patches are delivered dermally (Figure 5). Resident antigen presenting cells (APCs) are more abundant and diverse in the dermis compared to the s.c. tissue; ${ }^{42-44}$ differences in charge and hydrophobicity of the peptide epitopes may alter release from the MN patches and impact in vivo trafficking and subsequent processing by APCs. Data may indicate more effective processing of the peptide epitope 826, which is highly positively charged (Figure 6B). The reduced antibody levels may be explained also by delivery of a reduced dose using the $\mathrm{MN}$ approach: here the active ingredient, i.e., $3 \mathrm{Q} \beta$ vaccine candidate, is released only from the needles, making the base of the MN patch a void volume. We performed a BCA protein assay (Thermo Fisher Scientific) to determine the actual amount of $\mathrm{Q} \beta$ vaccine loaded into the needles and concluded that $\sim 10 \%$ of the total protein $(\mathrm{Q} \beta$ vaccine $)$ is released from the needles. Thus, to produce a $100 \mu \mathrm{g}$ dose per $\mathrm{Q} \beta$ candidate, a total of $1 \mathrm{mg}$ of $\mathrm{Q} \beta$ per candidate or total of 3 $\mathrm{mg}$ of protein would need to be loaded per MN patch. The maximum loading dose however was $1.5 \mathrm{mg}$ of protein, which equates to $500 \mu \mathrm{g}$ per $\mathrm{Q} \beta$ candidate, thus providing an effective dose of $\sim 50 \mu \mathrm{g}$ vs $100 \mu \mathrm{g}$ (used for the soluble injection). The limitation is the volume of the device and protein concentrations that could not be increased above $60 \mathrm{mg} / \mathrm{mL}$. From a translational point of view this is unlikely a barrier, as the $\mathrm{MN}$ patch size could be increased.

Antibody titers were monitored over 12 weeks; overall antibody titers were maintained with a slight decrease observed for the 636 and 570 peptide formulations (Figure 6B and Figure 4B). Again, the data demonstrate the potency of the 826 formulations, which maintained high titers of antibodies over the 3-month time course (later time points were not considered). Our next goal was then to establish what immunoglobulin isotypes (IgG subclasses: IgG1, IgG2a, $\operatorname{IgG} 2$ b, IgG2b, IgG2c, IgG3; IgM, IgE) were provoked. IgG1 is a subclass of IgG that are known to be primarily induced via Th2-type cytokines (e.g., interleukin-4 (IL-4)), and the generation of IgG2a antibodies is involved with the presence of Th1-type cytokines (e.g., interferon-gamma (IFN- $\gamma$ )). ${ }^{6,45}$ Data indicate that IgG2a/IgG1 ratios remained essentially the same between groups, and IgG2a/IgG1 ratios were $\geq 1$ (Figure $6 \mathrm{C})$. Interestingly, the $3 \mathrm{Q} \beta \mathrm{MN}$ active group showed a ratio of $<1$ for any epitope tested (Figure S3C). Therefore, vaccine candidates produced a Th1/Th2 balanced immune response, except for the $3 \mathrm{Q} \beta \mathrm{MN}$ active group, which exhibited a Th2biased profile (Figure S3C); the production of hydrogen as a result of dissolving $\mathrm{Mg}$ particles used for the micromixing may influence the cytokine/chemokine profiles and therefore bias the immune response. We also tested for additional IgG isotypes and detected IgG2b at similar levels compared to IgG2a, indicating a slight bias toward a Th1 profile; IgG2c is not expressed in Balb/c and hence was not detected; IgM was perceived in all the groups and titers were dependent on the epitope used; last, IgE, an isotype related to allergic diseases was not detected, indicating safety (Figure S3). Comparing the profiles obtained for CPMV and $\mathrm{Q} \beta$, data indicate that both the epitope and carrier impact whether Th1 or Th2 bias is established.

We also assessed whether $\mathrm{T}$ cell activation was primed upon a single dose of monovalent or trivalent vaccine candidate s.c.; splenocytes were analyzed by ELISpot 14 days postadministration s.c. Stimulation of splenocytes with unmodified $\mathrm{Q} \beta$ yielded comparable levels of IFN- $\gamma$ and IL-4 when compared to positive 

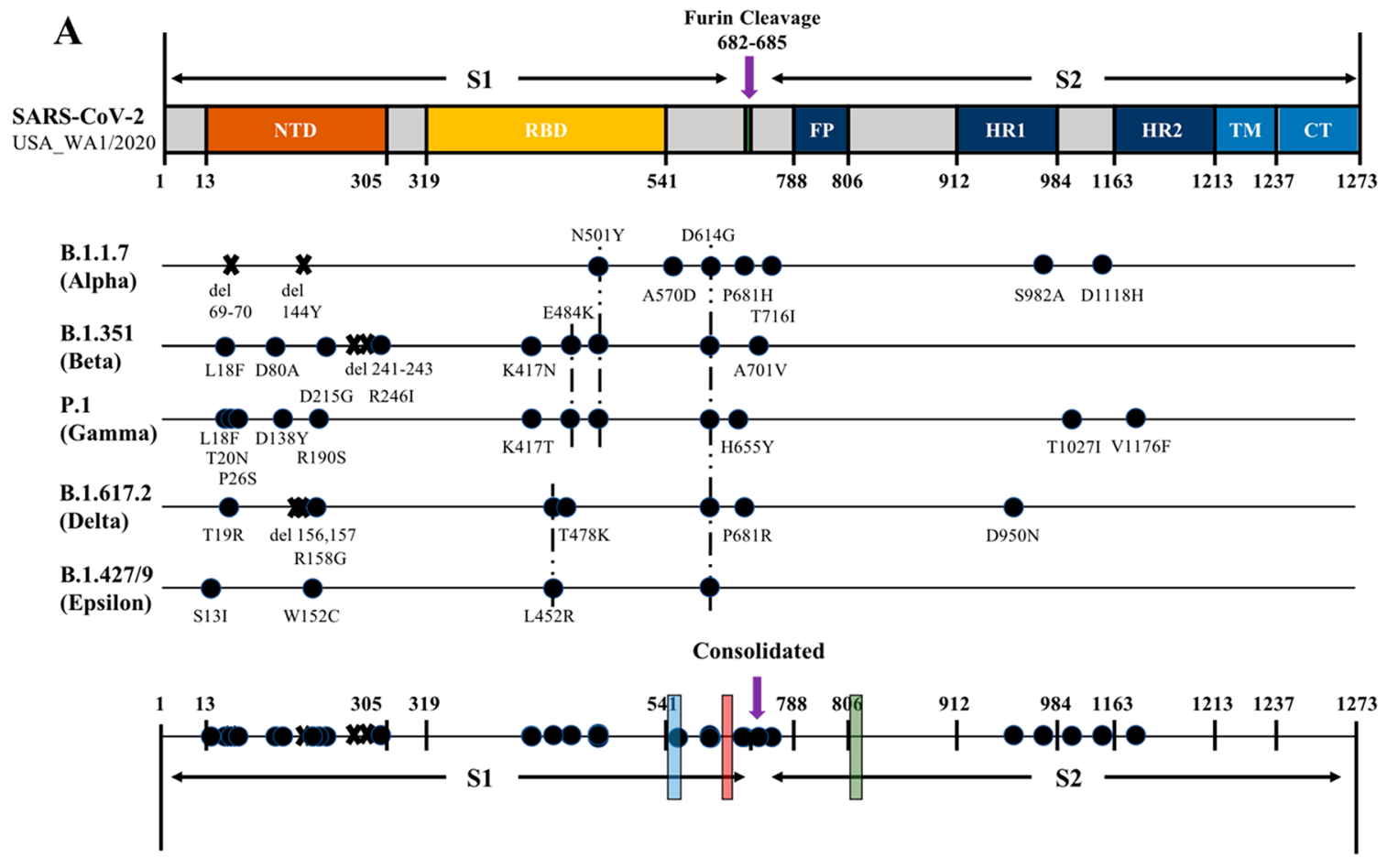

B

Peptide: 553-570 (neutralizing); Mutant A570D

\begin{tabular}{|c|c|c|}
\hline B. 1.1 .7 & GTGVLTESNKKFLPFQQFGRDIDDTTDAVRD & 578 \\
\hline B. 1.351 & GTGVLTESNKKFLPFQQFGRDIADTTDAVRD & 578 \\
\hline P. 1 & GTGVLTESNKKFLPFQQFGRDIADTTDAVRD & 578 \\
\hline .1 .617 .2 & GTGVLTESNKKFLPFQQFGRDIADTTDAVRD & 578 \\
\hline $1.427 / 9$ & GTGVLTESNKKFLPFQQFGRDIADTTDAVRD & 578 \\
\hline ARS-COV-2 & GTGVLTESNKKFLPFQQFGRDIADTTDAVRD & 578 \\
\hline ARS-COV & 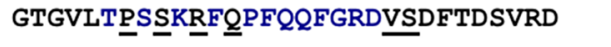 & 564 \\
\hline le: & $625-636$ (neutralizing) & \\
\hline B 1.1 .7 & EVPVAIHADQLTPTWRVYSTGSNVF & 643 \\
\hline 31.351 & EVPVAIHADQLTPTWRVYSTGSNVF & 643 \\
\hline P. 1 & EVPVAIHADQLTPTWRVYSTGSNVF & 643 \\
\hline B. 1.617 .2 & EVPVAIHADQLTPTWRVYSTGSNVF & 643 \\
\hline B. $1.427 / 9$ & EVPVAIHADQLTPTWRVYSTGSNVF & 643 \\
\hline SARS-COV-2 & EVPVAIHADQLTPTWRVYSTGSNVF & 643 \\
\hline SARS-COV & DVSTAIHADQLTPAWRIYSTGNNVF & 629 \\
\hline Pep & 809-826 (neutralizing) & \\
\hline B 1.1 .7 & NFSQILPDPSKPSKRSFIEDLLFNKVTLADAGF & 851 \\
\hline B 1.351 & NFSQILPDPSKPSKRSFIEDLLFNKVTLADAGF & 851 \\
\hline P. 1 & NFSQILPDPSKPSKRSFIEDLLFNKVTLADAGF & 851 \\
\hline B. 1.617 .2 & NFSQILPDPSKPSKRSFIEDLLFNKVTLADAGF & 851 \\
\hline B. $1.427 / 9$ & NFSQILPDPSKPSKRSFIEDLLFNKVTLADAGF & 851 \\
\hline & NFSQILPDPSKPSKRSFIEDLLFNKVTLADAGF & 851 \\
\hline Cov & RSFIEDLLFNKVTLADAGF & 833 \\
\hline
\end{tabular}

C

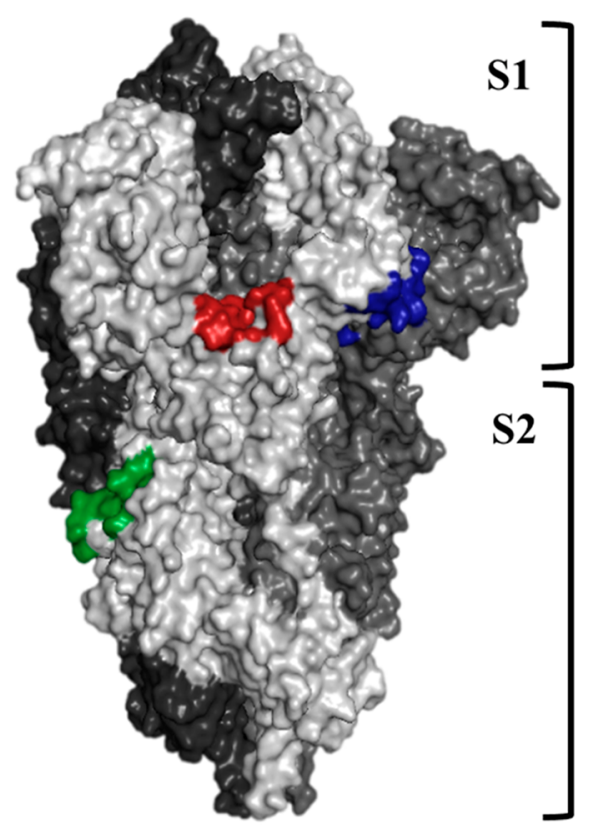

Figure 8. SARS-CoV-2 S protein mutations from variants of concern (VOCs). (A) Punctual mutations that are unique or shared among VOCs are represented for each variant and then consolidated. ${ }^{47,48} \mathrm{~S}$ protein length is not to scale. (B) B cell epitope alignment and $\mathrm{S}$ protein model. Amino acid alignment of the validated epitopes $(570,636$, and 826$)$ and surrounding regions for reference SARS-CoV-2 (USA WA1/2020), SARS, and the variants of interest. Underlined amino acids represent the punctual mutations. (C) 3D model of the trimeric prefusion SARS-CoV-2 S protein. Highlighted colors indicate the actual position of the corresponding epitopes: blue $=553-570$, red $=625-636$, and green $=809-826$.

control PMA/ionomycin (Figure 6D). T cell responses against the vaccination platform, the $\mathrm{Q} \beta \mathrm{VLP}$, was expected due to the VLPs containing a mixture of epitopes. ${ }^{12}$ When stimulated with $S$ protein, IFN- $\gamma$ and IL-4 secretion was observed for any vaccine candidate, which is in agreement with the Th1/Th2 balanced immune response (see Figure 6C,D).

Immunogenicity against Recombinant S Protein. ELISA assays confirmed that $\mathrm{Q} \beta$-based COVID-19 vaccine 
candidates, mono- or trivalent, and delivered as soluble vaccine or via vaccine delivery devices yielded antibody responses recognizing intact SARS-CoV-2 S protein (Figure 7A). Furthermore, the sVNT assay confirmed that antibodies from all vaccination groups were effective at inhibiting RBD-ACE2 interactions (Figure 7B). Overall, data indicated that the epitopes 570, 636, and 826 produce robust immune responses against SARS-CoV-2 S protein, and epitopes can be transferred from one to another vaccination platform. Lastly, while we did not observe a synergistic effect when using the trivalent vaccine formulations in the RBD-based neutralization assay, it is possible that the trivalent vaccine candidate would produce synergistic or enhanced neutralization effects in vivo. Peptides 636 and 826 are located near the furin cleavage site and fusion peptide, respectively (Figure $7 \mathrm{~A}$ ). It is also possible that the neutralization mechanism occurs during the viral fusion and not by blocking the RBD-ACE2 binding. Therefore, further experiments in vivo are required to establish an additive or synergistic effect of trivalent as compared to monovalent versions.

SARS-CoV-2 Variants and the Trivalent Vaccine Candidates. Since the beginning of the pandemic, variants of SARS-CoV-2 have been reported with mutations occurring in the $S$ protein. ${ }^{46-48}$ The SARS-CoV-2 S protein is a class I fusion protein produced as a large 1273 amino acid inactive precursor (S0). Proteolytic cleavage of the S protein generates the highly variable $S 1$ subunit and $S 2$ subunit, which is conserved across human coronaviruses. ${ }^{49,50}$ The N-terminal domain (NTD) and the receptor-binding domain (RBD) are located in the $\mathrm{S} 1$ subunit. The fusion peptide (FP), two heptad repeats (HR1 and HR2), central helix ( $\mathrm{CH})$, transmembrane (TM) domain, and cytoplasmic tail (CT) are located in the S2 subunit. Three S1/S2 protomers noncovalently associated to form the functional Strimer. ${ }^{51}$ Mutations and emergence of variants are natural responses of the virus to selective pressure either to chronic COVID-19 development, to vaccination, or to antiviral treatments. Four hundred distinct mutation sites were reported in the $S 1$ and $S 2$ regions, with the highest frequency of mutations occurring in the S1/RBD region. ${ }^{49}$ Not surprisingly, VOCs harbor numerous RBD mutations with troubling characteristics such as greater binding affinity (up to 10 -fold) with the hACE2 receptor as one of the main contributing factors toward increased infectivity (B 1.1.7/N501Y) ${ }^{52}$ and complete evasion from current monoclonal antibody therapy (Bamlanivimab) of B1.351/501Y.V2 and P1/501Y.V3. ${ }^{49}$ Among the 13 B-cell epitopes in our peptide library, five peptide sequences $(106,153$, $420,454,570)$ contain mutations present in one or more VOCs (Table S2). Notably, all these mutations are located in the S1 subunit, and two are located in the RBD (Figure 8A). Among the validated epitopes $(570,636,826)$ only epitope 570 has a single substitution present in the B 1.1.7 variant (A570D), located in the N-terminal domain. Peptide epitopes 636 and 826 are not affected by the mutations reported to date, therefore showing promise as broadly neutralizing vaccine candidates (Figure $8 \mathrm{~B}$ ). While a mutation within the 636 epitope sequence has not yet occurred, mutations have been reported in the surroundings of the furin cleavage sequence (D614G, P681H, H655Y, A701V, T716I), suggesting that this area is susceptible to mutations. Of remarkable attention is the epitope 826 , which is situated in the S2 domain adjacent to the fusion protein region and outside of the HR1 and HR2 regions. The low degree of mutation rate in this region ${ }^{49}$ and the high degree of homology between SARSCoV-2 and SARS within the 18AA peptide consensus sequence
(Figure 8) make this an attractive target for vaccine development. The CPMV826 vaccine candidate yielded high neutralizing antibody titers, comparable to Moderna's vaccine, ${ }^{36,53}$ highlighting the functional relevance of this epitope. The underlying mechanism for the high neutralizing titer against the 826 epitope warrants further investigation. Finally, we tested CPMV-570, CPMV-636, and CPMV-826 against SARS-CoV to corroborate the cross-reactivity with other coronaviruses. CPMV-636 and CPMV-826 showed a neutralization titer of 1:480 and CPMV-570 a titer of 1:240 (Table S3).

\section{CONCLUSION}

We screened 13 peptide epitope candidates and identified three target epitopes $(570,636$, and 826$)$ from SARS-CoV-2 S protein to be suitable for vaccine design. The effective $B$ cell epitopes, originally identified from convalescent sera from recovered COVID-19 patients, were formulated using viral platform display technology, namely, CPMV and $\mathrm{Q} \beta$ VLPs. Immunization of mice using mono- and trivalent vaccine candidates administered as a soluble prime-boost injection, $\mathrm{MN}$ patch technology or injectable slow-release implant demonstrated efficacy yielding SARS-CoV-2 neutralizing antibodies and balanced Th1/Th2 immune response. Importantly, sequence analysis of SARS-CoV-2 VOCs indicates that the three epitopes, which are not located in the RBD domain, are highly conserved among the VOCs and other coronaviruses, which may enable the development of a pan-coronavirus vaccine. The proposed $B$ cell epitope-based approach, as opposed to vaccination against full-length $S$ protein, is expected to give rise to more targeted vs broad-spectrum antibody and cellular responses, which may yield focused vaccines on conserved domains with antibody responses consistently targeting and neutralizing across VOCs. An important consideration is also that the plant virus and bacteriophage-based nanotechnologies offer high thermal stability, thus overcoming the need for cold-chain storage and distribution. These platform vaccine technologies are sufficiently stable to allow for device formulation through polymer melt processing and casting processes, a scalable manufacturing platform that may provide access to single-dose devices that can be easily transported throughout the world and may be selfadministered. The technology presented here offers a highly versatile vaccination platform technology that can be pivoted toward other diseases.

\section{ASSOCIATED CONTENT}

\section{SI Supporting Information}

The Supporting Information is available free of charge at https://pubs.acs.org/doi/10.1021/jacs.1c06600.

Figures S1-S5, Tables S1-S3, and experimental methods (PDF)

\section{AUTHOR INFORMATION}

\section{Corresponding Authors}

Nicole F. Steinmetz - Department of NanoEngineering, Center for Nano-ImmunoEngineering, Institute for Materials Discovery and Design, Department of Bioengineering, Department of Radiology, and Moores Cancer Center, University of California-San Diego, La Jolla, California 92039, United States; 이이이.org/0000-0002-0130-0481; Email: nsteinmetz@ucsd.edu

Jonathan K. Pokorski - Department of NanoEngineering, Center for Nano-ImmunoEngineering, and Institute for 
Materials Discovery and Design, University of California-San Diego, La Jolla, California 92039, United States; ๑๐ orcid.org/0000-0001-5869-6942; Email: jpokorski@ ucsd.edu

\section{Authors}

Oscar A. Ortega-Rivera - Department of NanoEngineering and Center for Nano-ImmunoEngineering, University of California-San Diego, La Jolla, California 92039, United States; (1) orcid.org/0000-0002-0773-0677

Matthew D. Shin - Department of NanoEngineering and Center for Nano-ImmunoEngineering, University of California-San Diego, La Jolla, California 92039, United States

Angela Chen - Department of NanoEngineering and Center for Nano-ImmunoEngineering, University of California-San Diego, La Jolla, California 92039, United States

Veronique Beiss - Department of NanoEngineering and Center for Nano-ImmunoEngineering, University of California-San Diego, La Jolla, California 92039, United States

Miguel A. Moreno-Gonzalez - Department of NanoEngineering and Center for Nano-ImmunoEngineering, University of California-San Diego, La Jolla, California 92039, United States; ㅇ orcid.org/0000-0002-1601-9369

Miguel A. Lopez-Ramirez - Department of NanoEngineering, University of California-San Diego, La Jolla, California 92039, United States

Maria Reynoso - Department of NanoEngineering, University of California-San Diego, La Jolla, California 92039, United States; Institute for Antiviral Research, Utah State University, Logan, Utah 84322, United States

Hong Wang - Department of Bioengineering, University of California-San Diego, La Jolla, California 92039, United States

Brett L. Hurst - Department of Bioengineering, University of California-San Diego, La Jolla, California 92039, United States; Institute for Antiviral Research, Utah State University, Logan, Utah 84322, United States

Joseph Wang - Department of NanoEngineering and Center for Nano-ImmunoEngineering, University of California-San Diego, La Jolla, California 92039, United States

Complete contact information is available at:

https://pubs.acs.org/10.1021/jacs.1c06600

\section{Author Contributions}

The manuscript was written through contributions of all authors./All authors have given approval to the final version of the manuscript.

\section{Notes}

The authors declare the following competing financial interest(s): Drs. Steinmetz and Pokorski are co-founders of and have a financial interest with Mosaic ImmunoEngineering Inc. The other authors declare no conflicts of interest.

\section{ACKNOWLEDGMENTS}

This work was funded in part by the following grant from the NSF (RAPID CMMI-2027668 to N.F.S. and J.K.P.) as well as partially supported by the NSF through the UC San Diego Materials Research Science and Engineering Center (UCSD MRSEC), DMR-2011924 (to N.F.S., J.K.P.). O.A.O.R. acknowledges the UC MEXUS-CONACYT Postdoctoral Fellowship 2019-2020 number FE-19-58 and 2020-2021 number FE-20-136. M.A.-L.R. and M.R acknowledge the UC MEXUS-CONACYT Doctoral Fellowships. UC San Diego has utilized the nonclinical and preclinical services program offered by the National Institute of Allergy and Infectious Diseases. Figures 1, 4-6, and S5 and the TOC were partially prepared using Biorender.com.

\section{REFERENCES}

(1) Wang, C.; Horby, P. W.; Hayden, F. G.; Gao, G. F. A Novel Coronavirus Outbreak of Global Health Concern. Lancet 2020, 395 (10223), 470-473.

(2) Corey, B. L.; Mascola, J. R.; Fauci, A. S.; Collins, F. S. A Strategic Approach to COVID-19 Vaccine R\&D. Science 2020, 368 (6494), 948-950.

(3) Ritchie, H.; Mathieu, E.; Rodés-Guirao, L.; Appel, C.; Giattino, C.; Ortiz-Ospina, E.; Hasell, J.; Macdonald, B.; Beltekian, D.; Roser, M. 2020 - "Coronavirus Pandemic (COVID-19)". Published online at OurWorldInData.org. Retrieved from: https://ourworldindata.org/ coronavirus (last accessed on 04/01/2021).

(4) Shukla, S.; Myers, J. T.; Woods, S. E.; Gong, X.; Czapar, A. E.; Commandeur, U.; Huang, A. Y.; Levine, A. D.; Steinmetz, N. F. Plant Viral Nanoparticles-Based HER2 Vaccine: Immune Response Influenced by Differential Transport, Localization and Cellular Interactions of Particulate Carriers. Biomaterials 2017, 121, 15-27.

(5) Mohsen, M. O.; Augusto, G.; Bachmann, M. F. The 3Ds in Viruslike Particle Based-Vaccines: "Design, Delivery and Dynamics. Immunol. Rev. 2020, 296 (1), 155-168.

(6) Bachmann, M. F.; Jennings, G. T. Vaccine Delivery: A Matter of Size, Geometry, Kinetics and Molecular Patterns. Nat. Rev. Immunol. 2010, 10 (11), 787-796.

(7) Lin, T.; Chen, Z.; Usha, R.; Stauffacher, C. V.; Dai, J. B.; Schmidt, T.; Johnson, J. E. The Refined Crystal Structure of Cowpea Mosaic Virus at 2.8 Å Resolution. Virology 1999, 265 (1), 20-34.

(8) Rybicki, E. P. Plant-Based Vaccines against Viruses. Virol. J. 2014, 11 (1), 1-20.

(9) Lizotte, P. H.; Wen, A. M.; Sheen, M. R.; Fields, J.; Rojanasopondist, P.; Steinmetz, N. F.; Fiering, S. In Situ Vaccination with Cowpea Mosaic Virus Nanoparticles Suppresses Metastatic Cancer. Nat. Nanotechnol. 2016, 11 (3), 295-303.

(10) Shukla, S.; Jandzinski, M.; Wang, C.; Gong, X.; Bonk, K. W.; Keri, R. A.; Steinmetz, N. F. A Viral Nanoparticle Cancer Vaccine Delays Tumor Progression and Prolongs Survival in a HER2 + Tumor Mouse Model. Advanced Therapeutics 2019, 2 (4), 1800139.

(11) Chariou, P. L.; Ortega-Rivera, O. A.; Steinmetz, N. F. Nanocarriers for the Delivery of Medical, Veterinary, and Agricultural Active Ingredients. ACS Nano 2020, 14 (3), 2678-2701.

(12) Ortega-Rivera, O. A.; Pokorski, J. K.; Steinmetz, N. F. A SingleDose, Implant-Based, Trivalent Virus-like Particle Vaccine against "Cholesterol Checkpoint" Proteins. Advanced Therapeutics 2021, 2100014, 2100014.

(13) Shao, S.; Ortega-Rivera, O. A.; Ray, S.; Pokorski, J. K.; Steinmetz, N. F. A Scalable Manufacturing Approach to Single Dose Vaccination against Hpv. Vaccines 2021, 9 (1), 1-15.

(14) Boone, C. E.; Wang, C.; Lopez-Ramirez, M. A.; Beiss, V.; Shukla, S.; Chariou, P. L.; Kupor, D.; Rueda, R.; Wang, J.; Steinmetz, N. F. Active Microneedle Administration of Plant Virus Nanoparticles for Cancer in Situ Vaccination Improves Immunotherapeutic Efficacy. ACS Applied Nano Materials 2020, 3 (8), 8037-8051.

(15) Shin, M. D.; Shukla, S.; Chung, Y. H.; Beiss, V.; Chan, S. K.; Ortega-Rivera, O. A.; Wirth, D. M.; Chen, A.; Sack, M.; Pokorski, J. K.; Steinmetz, N. F. COVID-19 Vaccine Development and a Potential Nanomaterial Path Forward. Nat. Nanotechnol. 2020, 15 (8), 646-655.

(16) Chung, Y. H.; Beiss, V.; Fiering, S. N.; Steinmetz, N. F. Covid-19 Vaccine Frontrunners and Their Nanotechnology Design. ACS Nano 2020, 14 (10), 12522-12537.

(17) Wu, Y.; Wang, F.; Shen, C.; Peng, W.; Li, D.; Zhao, C.; Li, Z.; Li, S.; Bi, Y.; Yang, Y.; Gong, Y.; Xiao, H.; Fan, Z.; Tan, S.; Wu, G.; Tan, W.; Lu, X.; Fan, C.; Wang, Q.; Liu, Y.; Zhang, C.; Qi, J.; Gao, G. F.; Gao, F.; 
Liu, L. A Non-Competing Pair of Human Neutralizing Antibodies Block COVID-19 Virus Binding to Its Receptor ACE2. Science 2020, 368 (6496), 1274-1278.

(18) Liu, Z.; VanBlargan, L. A.; Bloyet, L. M.; Rothlauf, P. W.; Chen, R. E.; Stumpf, S.; Zhao, H.; Errico, J. M.; Theel, E. S.; Liebeskind, M. J.; Alford, B.; Buchser, W. J.; Ellebedy, A. H.; Fremont, D. H.; Diamond, M. S.; Whelan, S. P. J. Identification of SARS-CoV-2 Spike Mutations That Attenuate Monoclonal and Serum Antibody Neutralization. Cell Host Microbe 2021, 29 (3), 477-488.

(19) Wang, Q.; Zhang, L.; Kuwahara, K.; Li, L.; Liu, Z.; Li, T.; Zhu, H.; Liu, J.; Xu, Y.; Xie, J.; Morioka, H.; Sakaguchi, N.; Qin, C.; Liu, G. Immunodominant SARS Coronavirus Epitopes in Humans Elicited Both Enhancing and Neutralizing Effects on Infection in Non-Human Primates. ACS Infect. Dis. 2016, 2 (5), 361-376.

(20) Lee, W. S.; Wheatley, A. K.; Kent, S. J.; DeKosky, B. J. AntibodyDependent Enhancement and SARS-CoV-2 Vaccines and Therapies. Nature Microbiology 2020, 5 (10), 1185-1191.

(21) Hotez, P. J.; Corry, D. B.; Bottazzi, M. E. COVID-19 Vaccine Design: The Janus Face of Immune Enhancement. Nat. Rev. Immunol. 2020, 20 (6), 347-348.

(22) Lauer, K. B.; Borrow, R.; Blanchard, T. J. Multivalent and Multipathogen Viral Vector Vaccines. Clin. Vaccine Immunol. 2017, 24 (1), e00298-16.

(23) Wen, A. M.; Lee, K. L.; Yildiz, I.; Bruckman, M. A.; Shukla, S.; Steinmetz, N. F. Viral Nanoparticles for in Vivo Tumor Imaging. J. Visualized Exp. 2012, 69, DOI: 10.3791/4352.

(24) Huo, J.; Zhao, Y.; Ren, J.; Zhou, D.; Duyvesteyn, H. M. E.; Ginn, H. M.; Carrique, L.; Malinauskas, T.; Ruza, R. R.; Shah, P. N. M.; Tan, T. K.; Rijal, P.; Coombes, N.; Bewley, K. R.; Tree, J. A.; Radecke, J.; Paterson, N. G.; Supasa, P.; Mongkolsapaya, J.; Screaton, G. R.; Carroll, M.; Townsend, A.; Fry, E. E.; Owens, R. J.; Stuart, D. I. Neutralization of SARS-CoV-2 by Destruction of the Prefusion Spike. Cell Host Microbe 2020, 28 (3), 445-454.

(25) Wang, H.; Wu, X.; Zhang, X.; Hou, X.; Liang, T.; Wang, D.; Teng, F.; Dai, J.; Duan, H.; Guo, S.; Li, Y.; Yu, X. SARS-CoV-2 Proteome Microarray for Mapping COVID-19 Antibody Interactions at Amino Acid Resolution. ACS Cent. Sci. 2020, 6 (12), 2238-2249.

(26) Poh, C. M.; Carissimo, G.; Wang, B.; Amrun, S. N.; Lee, C. Y. P.; Chee, R. S. L.; Fong, S. W.; Yeo, N. K. W.; Lee, W. H.; Torres-Ruesta, A.; Leo, Y. S.; Chen, M. I. C.; Tan, S. Y.; Chai, L. Y. A.; Kalimuddin, S.; Kheng, S. S. G.; Thien, S. Y.; Young, B. E.; Lye, D. C.; Hanson, B. J.; Wang, C. I.; Renia, L.; Ng, L. F. P. Two Linear Epitopes on the SARSCoV-2 Spike Protein That Elicit Neutralising Antibodies in COVID-19 Patients. Nat. Commun. 2020, 11 (1), DOI: 10.1038/s41467-02016638-2.

(27) Li, Y.; Lai, D.; Zhang, H.; Jiang, H.; Tian, X.; Ma, M.; Qi, H.; Meng, Q.; Guo, S.; Wu, Y.; Wang, W.; Yang, X.; Shi, D.; Dai, J.; Ying, T.; Zhou, J.; Tao, S. ce. Linear Epitopes of SARS-CoV-2 Spike Protein Elicit Neutralizing Antibodies in COVID-19 Patients. Cell. Mol. Immunol. 2020, 17 (10), 1095-1097.

(28) Lu, S.; Xie, X. xiu; Zhao, L.; Wang, B.; Zhu, J.; Yang, T. rui; Yang, G. wen; Ji, M.; Lv, C. ping; Xue, J.; Dai, E.; Fu, X.; Liu, D.; Zhang, L.; Hou, S.; Yu, X.; Wang, Y.; Gao, H.; Shi, X.; Ke, C.; Ke, B.; Jiang, C.; Liu, R. The Immunodominant and Neutralization Linear Epitopes for SARS-CoV-2. Cell Rep. 2021, 34 (4), 108666.

(29) Lee, P. W.; Shukla, S.; Wallat, J. D.; Danda, C.; Steinmetz, N. F.; Maia, J.; Pokorski, J. K. Biodegradable Viral Nanoparticle/Polymer Implants Prepared via Melt-Processing. ACS Nano 2017, 11 (9), 87778789.

(30) Wirth, D. M.; Pokorski, J. K. Design and Fabrication of a LowCost Pilot-Scale Melt-Processing System. Polymer 2019, 181 (July), 121802.

(31) Reed, L. J.; Muench, H. A Simple Method of Estimating Fifty Percent Endpoints. Am. J. Epidemiol. 1938, 27, 493-98.

(32) Porta, C.; Spall, V. E.; Loveland, J.; Johnson, J. E.; Barker, P. J.; Lomonossoff, G. P. Development of Cowpea Mosaic Virus as a HighYielding System for the Presentation of Foreign Peptides. Virology 1994, 202 (2), 949-955.
(33) Usha, R.; Rohll, J. B.; Spall, V. E.; Shanks, M.; Maule, A. J.; Johnson, J. E.; Lomonossofft, G. P. Expression of an Animal Virus Antigenic Site on the Surface of a Plant Virus Particle. Virology 1993, 197, 366-374.

(34) Chatterji, A.; Ochoa, W. F.; Paine, M.; Ratna, B. R.; Johnson, J. E.; Lin, T. New addresses on an addressable virus nanoblock; uniquely reactive Lys residues on cowpea mosaic virus. Chem. Biol. 2004, 11 (6), 855-63.

(35) Raja, K. S.; Wang, Q.; Gonzalez, M. J.; Manchester, M.; Johnson, J. E.; Finn, M. G. Hybrid Virus-Polymer Materials. 1. Synthesis and Properties of PEG-Decorated Cowpea Mosaic Virus. Biomacromolecules 2003, 4 (3), 472-476.

(36) Corbett, K. S.; Edwards, D. K.; Leist, S. R.; Abiona, O. M.; Boyoglu-Barnum, S.; Gillespie, R. A.; Himansu, S.; Schäfer, A.; Ziwawo, C. T.; DiPiazza, A. T.; Dinnon, K. H.; Elbashir, S. M.; Shaw, C. A.; Woods, A.; Fritch, E. J.; Martinez, D. R.; Bock, K. W.; Minai, M.; Nagata, B. M.; Hutchinson, G. B.; Wu, K.; Henry, C.; Bahl, K.; GarciaDominguez, D.; Ma, L. Z.; Renzi, I.; Kong, W. P.; Schmidt, S. D.; Wang, L.; Zhang, Y.; Phung, E.; Chang, L. A.; Loomis, R. J.; Altaras, N. E.; Narayanan, E.; Metkar, M.; Presnyak, V.; Liu, C.; Louder, M. K.; Shi, W.; Leung, K.; Yang, E. S.; West, A.; Gully, K. L.; Stevens, L. J.; Wang, N.; Wrapp, D.; Doria-Rose, N. A.; Stewart-Jones, G.; Bennett, H.; Alvarado, G. S.; Nason, M. C.; Ruckwardt, T. J.; McLellan, J. S.; Denison, M. R.; Chappell, J. D.; Moore, I. N.; Morabito, K. M.; Mascola, J. R.; Baric, R. S.; Carfi, A.; Graham, B. S. SARS-CoV-2 MRNA Vaccine Design Enabled by Prototype Pathogen Preparedness. Nature 2020, 586 (7830), 567-571.

(37) Ambühl, P. M.; Tissot, A. C.; Fulurija, A.; Maurer, P.; Nussberger, J.; Sabat, R.; Nief, V.; Schellekens, C.; Sladko, K.; Roubicek, K.; Pfister, T.; Rettenbacher, M.; Volk, H. D.; Wagner, F.; Müller, P.; Jennings, G. T.; Bachmann, M. F. A vaccine for hypertension based on virus-like particles: preclinical efficacy and phase I safety and immunogenicity. J. Hypertens. 2007, 25 (1), 63-72.

(38) Pan, Y.; Zhou, Y.; Wu, H.; Chen, X.; Hu, X.; Zhang, H.; Zhou, Z.; Qiu, Z.; Liao, Y. A Therapeutic Peptide Vaccine Against PCSK9. Sci. Rep. 2017, 7 (1), 1-10.

(39) Khan, F.; Porter, M.; Schwenk, R.; DeBot, M.; Saudan, P.; Dutta, S. Head-to-Head Comparison of Soluble vs. $\mathrm{Q} \beta$ VLP Circumsporozoite Protein Vaccines Reveals Selective Enhancement of NANP Repeat Responses. PLoS One 2015, 10 (11), 1-18.

(40) Cai, H.; Shukla, S.; Wang, C.; Masarapu, H.; Steinmetz, N. F. Heterologous Prime-Boost Enhances the Antitumor Immune Response Elicited by Plant-Virus-Based Cancer Vaccine. J. Am. Chem. Soc. 2019, 141 (16), 6509-6518.

(41) Lopez-Ramirez, M. A.; Soto, F.; Wang, C.; Rueda, R.; Shukla, S.; Silva-Lopez, C.; Kupor, D.; McBride, D. A.; Pokorski, J. K.; Nourhani, A.; Steinmetz, N. F.; Shah, N. J.; Wang, J. Built-In Active Microneedle Patch with Enhanced Autonomous Drug Delivery. Adv. Mater. 2020, 32, 1905740.

(42) Schnyder, J. L.; De Pijper, C. A.; Garcia Garrido, H. M.; Daams, J. G.; Goorhuis, A.; Stijnis, C.; Schaumburg, F.; Grobusch, M. P. Fractional Dose of Intradermal Compared to Intramuscular and Subcutaneous Vaccination - A Systematic Review and Meta-Analysis. Travel Medicine and Infectious Disease 2020, 37, 101868.

(43) Combadiere, B.; Liard, C. Transcutaneous and Intradermal Vaccination. Hum. Vaccines 2011, 7 (8), 811-827.

(44) Kabashima, K.; Honda, T.; Ginhoux, F.; Egawa, G. The Immunological Anatomy of the Skin. Nat. Rev. Immunol. 2019, 19 (1), 19-30.

(45) Finkelman, F. D.; Holmes, J.; Katona, I. M.; Urban, J. F., Jr; Beckmann, M. P.; Park, L. S.; Schooley, K. A.; Coffman, R. L.; Mosmann, T. R.; Paul, W. E. Lymphokine control of in vivo immunoglobulin isotype selection. Annu. Rev. Immunol. 1990, 8, 303-33.

(46) Mercatelli, D.; Giorgi, F. M. Geographic and Genomic Distribution of SARS-CoV-2 Mutations. Front. Microbiol. 2020, 11 (July), 1-13. 
(47) Hodcroft, E. Institute of Social and Preventive Medicine University of Bern, Switzerland \& SIB Swiss Institute of Bioinformatics, Switzerland https://covariants.org/ (last accessed on 06/01/2021).

(48) Elbe, S., Buckland-Merrett, G. Data, disease and diplomacy: GISAID's innovative contribution to global health. Global Challenges. Global Challenges 2017, 1, 33-46.

(49) Coutard, B.; Valle, C.; de Lamballerie, X.; Canard, B.; Seidah, N. G.; Decroly, E. The Spike Glycoprotein of the New Coronavirus 2019NCoV Contains a Furin-like Cleavage Site Absent in CoV of the Same Clade. Antiviral Res. 2020, 176, 104742.

(50) Guruprasad, L. Human SARS CoV-2 Spike Protein Mutations. Proteins: Struct., Funct., Genet. 2021, 89 (5), 569-576.

(51) Walls, A. C.; Park, Y. J.; Tortorici, M. A.; Wall, A.; McGuire, A. T.; Veesler, D. Structure, Function, and Antigenicity of the SARS-CoV2 Spike Glycoprotein. Cell 2020, 181 (2), 281-292.

(52) Laffeber, C.; de Koning, K.; Kanaar, R.; Lebbink, J. H. G. Experimental Evidence for Enhanced Receptor Binding by Rapidly Spreading SARS-CoV-2 Variants. J. Mol. Biol. 2021, 433 (15), 167058. (53) Huang, Q.; Ji, K.; Tian, S.; Wang, F.; Huang, B.; Tong, Z.; Tan, S.; Hao, J.; Wang, Q.; Tan, W.; Gao, G. F.; Yan, J. A Single-Dose MRNA Vaccine Provides a Long-Term Protection for HACE2 Transgenic Mice from SARS-CoV-2. Nat. Commun. 2021, 12 (1), 1-10. 